Prepared for the U.S. U.S. Department of Energy

Under Contract DE-AC05-76RL01830

\title{
Under-Sodium Viewing: A Review of Ultrasonic Imaging Technology for Liquid Metal Fast Reactors
}
JW Griffin
TJ Peters
LJ Bond
GJ Posakony
KM Denslow
HT Chien
$\mathrm{SH}$ Sheen
AC Raptis

March 2009 


\title{
DISCLAIMER
}

This report was prepared as an account of work sponsored by an agency of the United States Government. Neither the United States Government nor any agency thereof, nor Battelle Memorial Institute, nor any of their employees, makes any warranty, express or implied, or assumes any legal liability or responsibility for the accuracy, completeness, or usefulness of any information, apparatus, product, or process disclosed, or represents that its use would not infringe privately owned rights. Reference herein to any specific commercial product, process, or service by trade name, trademark, manufacturer, or otherwise does not necessarily constitute or imply its endorsement, recommendation, or favoring by the United States Government or any agency thereof, or Battelle Memorial Institute. The views and opinions of authors expressed herein do not necessarily state or reflect those of the United States Government or any agency thereof.

\author{
PACIFIC NORTHWEST NATIONAL LABORATORY \\ operated by \\ BATTELLE \\ for the \\ UNITED STATES DEPARTMENT OF ENERGY \\ under Contract DE-AC05-76RL01830 \\ Printed in the United States of America \\ Available to DOE and DOE contractors from the \\ Office of Scientific and Technical Information, \\ P.O. Box 62, Oak Ridge, TN 37831-0062; \\ ph: (865) 576-8401 \\ fax: $(865) 576-5728$ \\ email: reports@adonis.osti.gov

\footnotetext{
Available to the public from the National Technical Information Service,

U.S. Department of Commerce, 5285 Port Royal Rd., Springfield, VA 22161

ph: (800) 553-6847

fax: (703) 605-6900

email: orders@ntis.fedworld.gov

online ordering: http://www.ntis.gov/ordering.htm
}

This document was printed on recycled paper.

(9/2003) 


\title{
Under-Sodium Viewing: A Review of Ultrasonic Imaging Technology for Liquid Metal Fast Reactors
}

\author{
JW Griffin \\ LJ Bond \\ TJ Peters \\ KM Denslow \\ GJ Posakony \\ HT Chien $^{(a)}$ \\ SH Sheen ${ }^{(a)}$ \\ AC Raptis $^{(a)}$
}

March 2009

Prepared for the

U.S. Department of Energy

Under Contract DE-AC05-76RL01830

Pacific Northwest National Laboratory Richland, Washington 99352

(a) Argonne National Laboratory Argonne, Illinois 



\section{Executive Summary}

This current report is a summary of information obtained in the "Information Capture" task of the U.S. DOE-funded "Under Sodium Viewing (USV) Project." The goal of the multi-year USV project is to design, build, and demonstrate a state-of-the-art prototype ultrasonic viewing system tailored for periodic reactor core in-service monitoring and maintenance inspections. The study seeks to optimize system parameters, improve performance, and re-establish this key technology area which will be required to support any new U.S. liquid-metal cooled fast reactors.

The earliest information presented herein dates from the early 1970s when the DOE Hanford Site and Argonne National Laboratory were supporting instrumentation development for sodium-cooled fast reactors (SFRs). The most recent U.S. advanced liquid metal reactor (ALMR) design was the Power Reactor Innovative Small Module (PRISM). The U.S.-sponsored design effort was discontinued in 1995; however, General Electric (GE) continued development up to year 2000. A number of other countries (especially India, Japan, France, and Great Britain) have built and operated fast, metal-cooled reactors and supporting diagnostic instrumentation for in-service inspections. Piezoelectric transducers have been reported in systems used to: (i) acquire in-core images; (ii) perform ultrasonic NDE inspections; and (iii) measure liquid sodium levels, detect structural anomalies, and detect leaks.

This study has served to identify important design parameters and options for an ultrasonic USV system. These include:

1. The preferred piezoelectric material for liquid sodium temperatures up to $260^{\circ} \mathrm{C}$ is lead zirconate titanate $(\mathrm{PZT})$. Higher Curie temperature $\left(\mathrm{T}_{\mathrm{c}}\right)$ materials such as lithium niobate and lead metaniobate have also been used.

2. Most demonstrated USV ultrasonic transducers are of the direct sodium immersion type. Only a few designs use an ultrasonic waveguide to isolate the transducer from the molten sodium.

3. Poor sodium wetting of the transducer face has been an issue. Degraded wetting results in inefficient mechanical (acoustic) coupling between the transducer and the liquid sodium working fluid.

Solutions have required either coating the transducer face (e.g., with evaporated or sputtered gold) or bonding a metal diaphragm to the transducer face (e.g., stainless steel or nickel).

4. Thermal shock damage to the piezoelectric transducer is an important issue. Fracture of piezoelectric ceramics due to high thermal gradients/transients or thermal expansion mismatches at the transducer face or backing layer must be considered early in the design process.

5. Cable length between the transducer and ultrasonic transceiver has a major impact on received signal amplitude. The minute electrical charges generated by the piezoelectric transducer dictate use of lowcapacitance, radiation-resistant, high-temperature cables, and cable length must be kept as short as possible. Impedance matching and signal conditioning must be considered.

6. To date, most ultrasonic USV systems have implemented either single-transducer or linear-transducer array geometries. Hence, the transducer head must be physically moved to produce an image. Only limited work (in Japan) has explored two-dimensional arrays and synthetic aperture focusing techniques, which would relax the transducer scanning requirement. 
7. Nearly all of the recently demonstrated USV systems have been retrofitted to existing metal-cooled fast reactor vessel designs. That is, accommodation of the imager was not considered during the reactor design process. Imager performance could likely be improved if reactor core spatial constraints could be loosened. This argues for including imager design during the reactor design process.

8. Design of ultrasonic USV systems would benefit from a predictive mathematical system model where a wide variety of piezoelectric transducer designs as well as a range of piezoelectric materials could more easily be investigated.

9. With technology available in the mid-1970s, through-wall fatigue cracks were reported to become invisible when immersed in sodium. The historic data are limited, but suggest a significant technical issue and the need for more work to fully understand the limits of ultrasonic diagnostics for inspection in sodium-cooled reactor applications.

10. A logical, low-risk USV development program could be conducted over a period of three years. The first year would focus on materials selection and demonstration (under sodium) of a scanned singletransducer imaging system. The second year would progress to an under-sodium demonstration of a scanned linear array system (similar to the 1970's Hanford Engineering Development Laboratory design). With this system, multichannel signal processing challenges could be addressed. Year three efforts would explore use of two-dimensional transducer arrays amenable to synthetic aperture focusing/imaging methods. This design could relax the requirement to translate the transducer assembly during image acquisition (now required with single-point and linear array imagers). 


\section{Acknowledgments}

This work was funded by the U.S. Department of Energy's Office of Nuclear Energy under the Advanced Fuel Cycle Initiative. The authors acknowledge the generous support of R.W. (Dick) Smith, one of the original developers of the Under Sodium Viewing System at the Hanford Engineering Development Laboratory in the early 1970s. 



\section{Acronyms and Abbreviations}

$\mathrm{AE}$

AIN

ALMR

ANL

BSTF

CLEM

CRBRP

CTE

DLC

DOE

EM

EVTM

FFTF

GE

HEDL

HTSF

IGCAR

LMFBR

MYRRHA

NDE

PCHE

PNNL

PRISM

PZT

SAFT

SFR

$\mathrm{S} / \mathrm{N}$

SPV

$\mathrm{T}_{\mathrm{C}}$

UKAEA

USV

WMO acoustic emission

aluminum nitride

advanced liquid metal reactor

Argonne National Laboratory

Bench Scale USV Test Facility

Closed-Loop Ex-Vessel Machine

Clinch River Breeder Reactor Project

coefficient of thermal expansion

diamond-like carbon

U.S. Department of Energy

electromagnetic

Ex-Vessel Transfer Machine

Fast Flux Test Facility

General Electric

Hanford Engineering Development Laboratory

High Temperature Sodium Facility

Indira Ghandi Center for Atomic Research

liquid metal fast breeder reactor

Multi-purpose hYbrid Research Reactor for High-tech Applications

non-destructive examination

printed circuit heat exchanger

Pacific Northwest National Laboratory

Power Reactor Innovative Small Module

lead zirconate titanate

synthetic aperture focusing techniques

sodium-cooled fast reactor

signal-to-noise ratio

spiraled sheet waveguide

Curie temperature

United Kingdom Atomic Energy Agency

under-sodium viewing

Waste Management Operations 



\section{Contents}

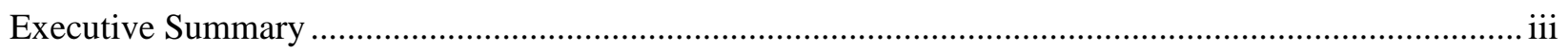

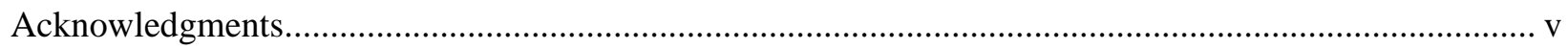

Acronyms and Abbreviations .......................................................................................................... vii

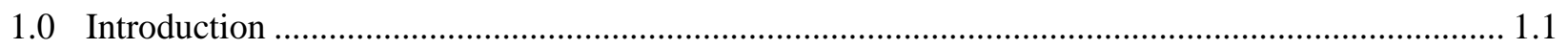

2.0 Operating Environment for Under-Sodium Viewing Systems …................................................ 2.1

2.1 Additional Diagnostic Sensors for Fast Reactors............................................................... 2.2

3.0 Testing Facilities for Under-Sodium Viewing Systems ........................................................... 3.1

3.1 USV Test System with Dump Tank .................................................................................... 3.3

4.0 Summary of International Research and Development Activities................................................ 4.1

4.1 Lithuania/Belgium.............................................................................................................. 4.1

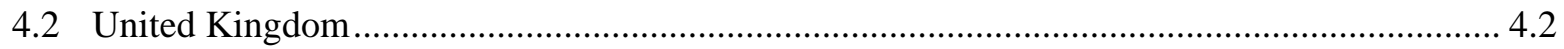

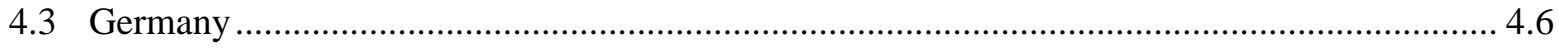

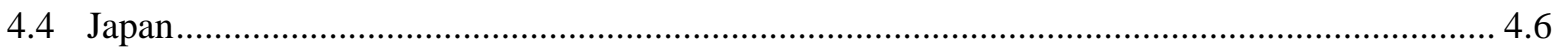

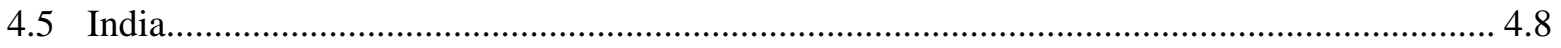

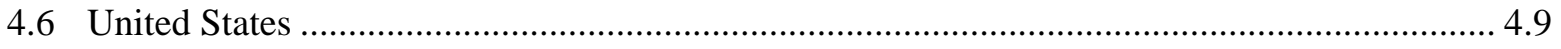

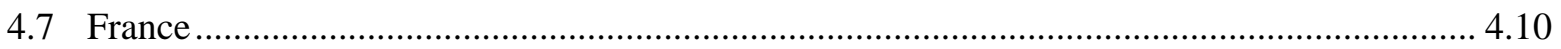

5.0 Design Considerations for Under-Sodium Viewing Systems..................................................... 5.11

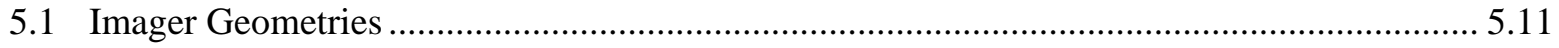

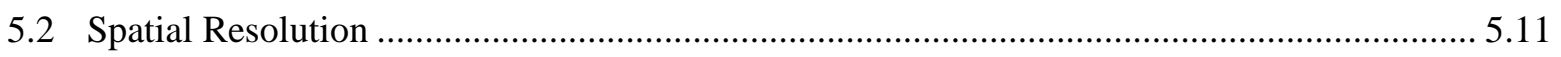

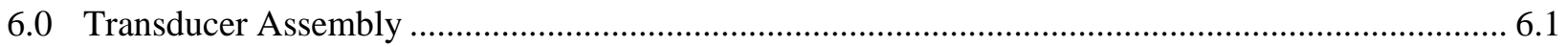

6.1 Mechanical and Synthetic Scanning to Obtain Ultrasonic Images ....................................... 6.7

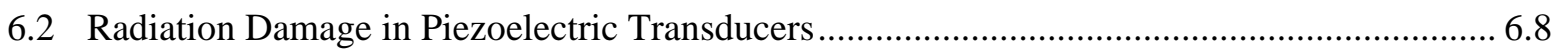

6.2.1 Alternative to Piezoelectric Transducers........................................................................ 6.8

7.0 High-Temperature Acoustic Waveguides..................................................................................... 7.1

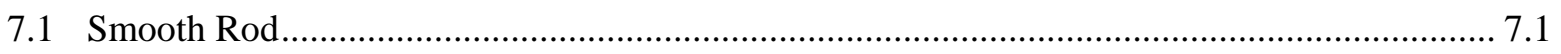

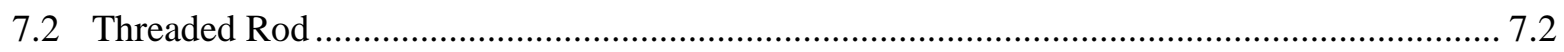

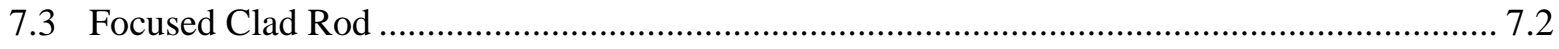

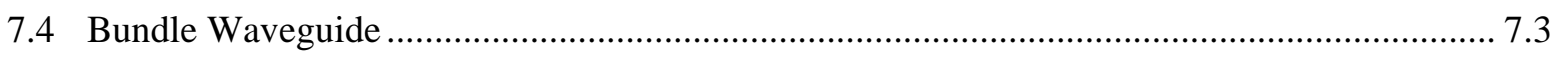

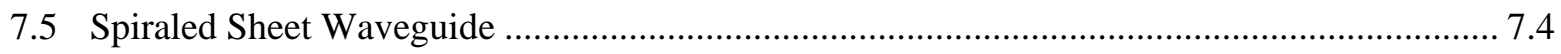

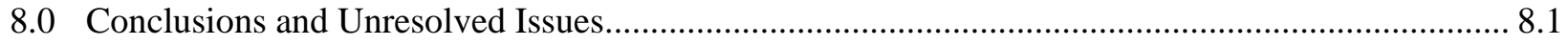

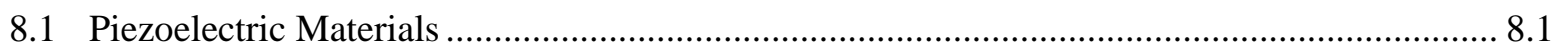

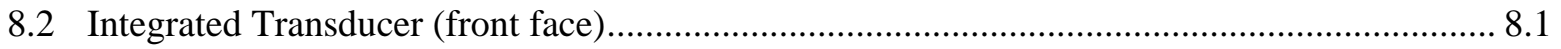

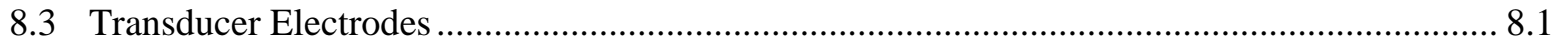

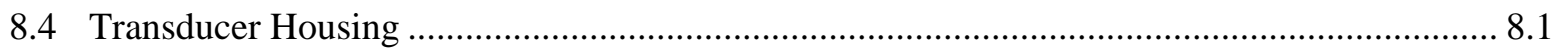

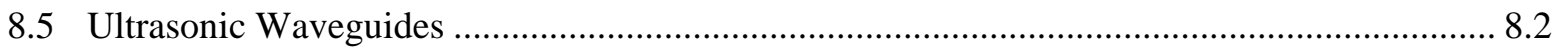

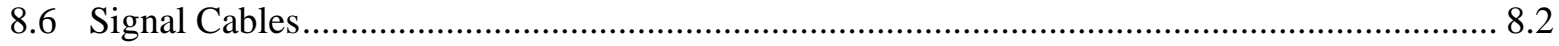




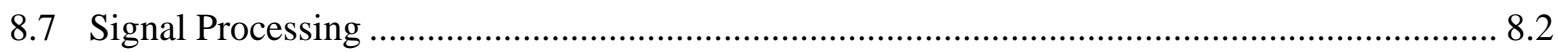

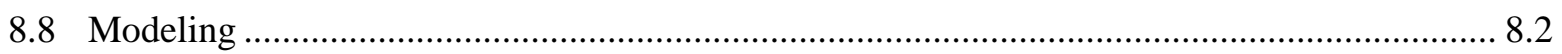

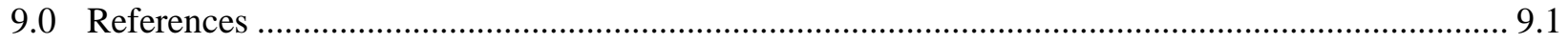




\section{Figures}

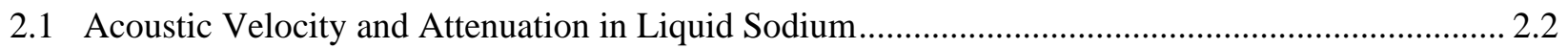

3.1 Sodium Plugging Test Facility at Argonne National Laboratory ..................................................... 3.2

3.2 USV Test Tank with Sodium Dump Tank....................................................................................... 3.3

4.1 Single-Element Detector for Imaging in Pb-Bi Alloy ................................................................ 4.2

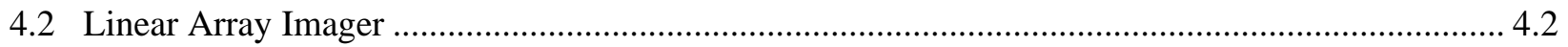

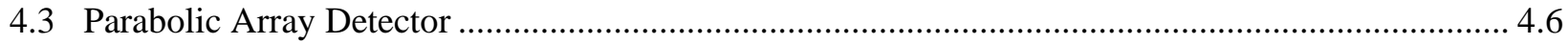

4.4 Toshiba Single-Element $\mathrm{LiNbO}_{3}$ Transducer ......................................................................... 4.7

4.5 Toshiba $36 \times 36$ Element PZT Array Transducer.................................................................... 4.7

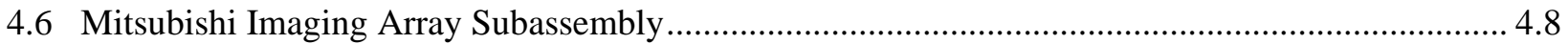

4.7 Scanned, Single-Transducer Assembly Tested in the Indian Fast Breeder Test............................. 4.8

4.8. Transducer Assembly and Scanning Array Designed for the Fast Flux Test Facility ...................... 4.9

4.9 Beam-forming System for Ultrasonic Scanning Using Orthogonal Linear Arrays ....................... 4.10

5.1 Ultrasonic Imager Configurations........................................................................................... 5.11

5.2 Transducer Beamwidth Calculations for Liquid Sodium ............................................................. 5.12

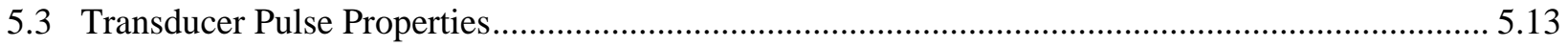

5.4 Ultrasonic Reflections from Stainless Steel Plate with Milled Letters ......................................... 5.13

5.5 Ultrasonic Image of Letters Milled into Back Surface of Stainless Steel Plate.............................. 5.14

6.1 Transducer Assembly Designed for Under-Sodium Viewing ......................................................... 6.1

6.2 Excitation Circuit for Piezoelectric Transducer .............................................................................. 6.7

6.3 Structural Difference between Piezoelectric and Optical Ultrasonic Transducers .......................... 6.9

6.4 Experimental Setup to Implement Optical Transducer Array ......................................................... 6.9

7.1 Smooth Rod Acoustic Waveguide Tested in the LMFBR Simulation Heat Transfer Loop.............. 7.2

7.2 Clad Buffer Rod with a Double-Taper Shape ............................................................................... 7.3

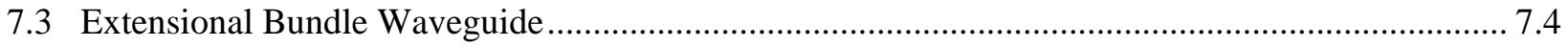

7.4 Schematic View and Photograph of the Spiraled Sheet Ultrasonic Waveguide ............................... 7.5

7.5 Additional High-Temperature Ultrasonic Waveguide Systems Developed at ANL ....................... 7.6

\section{Tables}

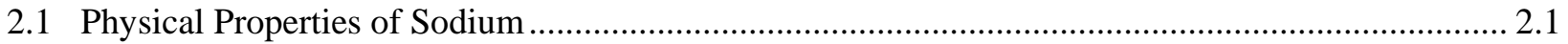

4.1 Summary of Worldwide Research and Development in Under-Sodium Viewing ........................... 4.3

6.1 Properties of Selected High-Temperature Piezoelectric Transducers............................................. 6.3

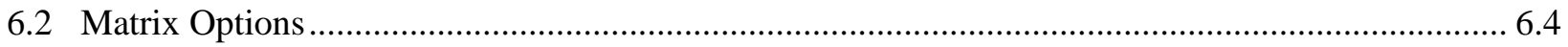





\subsection{Introduction}

It has been more than 30 years since the United States has pursued development of imaging systems for under-sodium viewing (USV) in fast breeder reactors. The information presented herein dates from the early 1970s when the DOE Hanford Site and Argonne National Laboratory were supporting instrumentation development for sodium-cooled fast reactors (SFRs). The most recent U.S. advanced liquid metal reactor (ALMR) design was the Power Reactor Innovative Small Module (PRISM). The U.S.-sponsored design effort was discontinued in 1995; however, General Electric (GE) continued development up until year 2000. A number of other countries (especially India, Japan, France, and Great Britain) have built and operated liquid-metal cooled fast reactors, as well as supporting diagnostic instrumentation for in-service inspections. The development of ultrasonic sensors for imaging, ranging, sodium-level detection, obstacle avoidance, sodium boiling, and sodium-water reactions (due to heat exchanger leaks) were pursued at both the Argonne National Laboratory in (ANL) in Illinois and at the Hanford Engineering Development Laboratory (HEDL) in Washington State. This report includes information obtained from an initial assessment of the state of the art (Bond et al. 2007a) and knowledge capture activities associated with records from the Fast Flux Test Facility (FFTF). Use of piezoelectric transducers has been reported in fast reactors, and other liquid-sodium and lead-bismuth systems. The transducers have been used to: (i) provide under sodium images; (ii) perform NDE core inspections; and (iii) acquire physical data in the liquid metal loop (sensors). These studies are summarized in this report. The work at these two laboratories represents two distinct approaches to sensing in high-temperature, molten metals.

In the first approach (ANL), the transducer is distanced from the high-temperature environment by the use of a metallic acoustic waveguide that propagates energy both to and from the molten metal. Only the distal end of the waveguide is in contact with the molten metal. This permits use of ceramic transducer materials with lower Curie temperatures (e.g., lead zirconate titanate [PZT]) and minimizes the likelihood of thermal shock damage to the transducer. Tests on the ANL ultrasonic waveguide system were conducted using the LMFBR (liquid metal fast breeder reactor) simulation heat transfer loop (Lynnworth et al. 2005) on the ANL campus. The waveguide approach is also used for imaging and inclusion detection in metal smelters where liquid metal temperatures can approach $1000^{\circ} \mathrm{C}$ (Ihara et al. 2000; Rehman et al. 2001; Ono et al. 2002a). In lightweight metal processing (e.g., aluminum and magnesium) quality is critically associated with inclusions within the molten metal during manufacturing steps.

In contrast, the Pacific Northwest National Laboratory (PNNL)-HEDL approach placed transducer assemblies in direct contact with and immersed in the molten sodium. This was possible because their system was intended for use during reactor shutdown when the sodium temperature ranged from 200-260 ${ }^{\circ}$. Work at HEDL in Washington State during the early to mid-1970s was performed under the direction of the U.S. Atomic Energy Agency. The HEDL work focused on: (1) developing sensors for measurement of liquid sodium level (Smith et al. 1974; Boehmer et al. 1975; Boehmer and Smith 1976); and (2) developing an ultrasonic imaging system for under-sodium viewing in the FFTF, a prototype sodium-cooled fast research reactor (Scott and Ying 1967; Becker and Trantow 1971; Ord and Smith 1972a, b; Day and Smith 1974a, b; Smith and Day 1975a). The under-sodium imaging system was intended for insertion into the FFTF during shutdown when sodium temperature ranged from $200-260^{\circ} \mathrm{C}$ and neutron flux had subsided. It was to be used for numerous inspections including: 
- visually observe the core region to ensure that handling machinery and other moving mechanisms could be maneuvered properly

- determine the elevation profile of the fuel duct assemblies (to quantify void swelling)

- identify each duct assembly (to verify fuel assemblies were where they were supposed to be)

- determine the operability of the fuel handling machine, including the grapple mechanism (to detect foreign objects that might interfere with fuel handling)

- evaluate the condition of the duct assembly handling sockets

- evaluate the condition of the instrument tree mechanisms

- check the operability and condition of the core restraint arms and jaws, if accessible

- provide calibration backup for determining handling machinery accuracy and position

- visualize azimuthal motion of the duct assemblies on release or on application of the core restraint system.

While the imaging system was never actually deployed at FFTF, its imaging capability was demonstrated under liquid sodium at the High Temperature Sodium Facility (HTSF) at HEDL in 1972 (Smith and Day 1975a). The HTSF was configured to accurately replicate the FFTF reactor vessel geometry to validate operability of the USV system prior to insertion. U.S. nuclear research and development priorities prevented its deployment even though the FFTF operated through 1992. Had the HEDL USV system proved successful at FFTF, it was slated for deployment at the Clinch River Breeder Reactor Project (CRBRP) to be built in Oak Ridge, Tennessee. However, funding for the CRBRP was terminated in 1983. 


\subsection{Operating Environment for Under-Sodium Viewing Systems}

This report provides a review and assessment of current and past worldwide research and development efforts with the intent of assembling the best design guidelines for an under-sodium viewing system. To that end, challenges associated with deploying an ultrasonic imaging system in the highradiation, high-temperature, hostile environment of the sodium fast reactor vessel are summarized below.

Fast reactors (as well as accelerator-driven reactors) use liquid metal as the core coolant and as the heat transfer fluid from the reactor core to the steam generator. While a variety of liquid metal coolants (e.g., mercury, sodium, lead bismuth) have been used worldwide, all of the current operating FBRs use liquid sodium. When the reactor is operating, sodium temperatures can reach $600^{\circ} \mathrm{C}$ with the potential for localized temperature excursions up to the boiling point of sodium $\left(883^{\circ} \mathrm{C}\right)$. Gamma radiation fields exceed $10^{10} \mathrm{R} / \mathrm{hr}$ and neutron fluxes are greater than $3 \times 10^{15} \mathrm{n} / \mathrm{cm}^{2} \mathrm{sec}$ (in Phenix). During maintenance outages, when the reactor is shut down, the neutron flux ceases, gamma levels decrease to $10^{10} \mathrm{R} / \mathrm{hr}$, and the coolant temperature is reduced to between $200-300^{\circ} \mathrm{C}$.

Because molten metals are optically opaque and electrically conductive, only ultrasonic imaging techniques can be used to image submerged portions of the reactor core, core supports, and refueling hardware. A summary of liquid sodium parameters relevant to sensor development appear in Table 2.1 and Figure 2.1 (Weast 1970; Foust 1972)

Table 2.1. Physical Properties of Sodium (Foust 1972)

\begin{tabular}{cllccc}
\hline $\begin{array}{c}\text { Temperature } \\
(\mathbf{C})\end{array}$ & $\begin{array}{c}\text { Density } \\
\left(\mathbf{g} / \mathbf{c m}^{3}\right)\end{array}$ & $\begin{array}{c}\text { Absolute } \\
\text { Viscosity } \\
(\mathbf{c e n t i p o i s e )}\end{array}$ & $\begin{array}{c}\text { Sonic } \\
\text { Velocity } \\
(\mathbf{m} / \mathbf{s e c})\end{array}$ & $\begin{array}{c}\text { Thermal } \\
\text { Conductivity } \\
(\mathbf{W} / \mathbf{c m}-\mathbf{C})\end{array}$ & $\begin{array}{c}\text { Electrical } \\
\text { Resistivity } \\
(\boldsymbol{\mu} \boldsymbol{\Omega} \mathbf{~ c m})\end{array}$ \\
\hline 100 & 0.9269 & 0.6802 & 2526 & 0.869 & 9.72 \\
150 & 0.9153 & 0.5415 & 2500 & 0.844 & 11.58 \\
\hline 200 & 0.9036 & 0.4519 & 2474 & 0.82 & 13.51 \\
\hline 250 & 0.8918 & 0.39 & 2448 & 0.796 & 15.52 \\
300 & 0.88 & 0.345 & 2422 & 0.771 & 17.61 \\
350 & 0.8681 & 0.311 & 2396 & 0.747 & 19.81 \\
400 & 0.8562 & 0.2845 & 2370 & 0.722 & 22.13 \\
450 & 0.8442 & 0.2633 & 2344 & 0.698 & 24.58 \\
\hline 500 & 0.8322 & 0.246 & 2318 & 0.673 & 27.17 \\
\hline 550 & 0.8202 & 0.2245 & 2292 & 0.649 & 29.91 \\
600 & 0.8082 & 0.2075 & 2266 & 0.624 & 32.81 \\
650 & 0.7961 & 0.1933 & 2240 & 0.56 & 35.9 \\
\hline 700 & 0.784 & 0.1813 & 2214 & 0.576 & 39.17 \\
\hline 750 & 0.7719 & 0.171 & 2188 & 0.55 & 42.65 \\
800 & 0.7598 & 0.1621 & 2162 & 0.526 & 46.35 \\
\hline 850 & 0.7477 & 0.1543 & 2136 & 0.502 & 50.27 \\
\hline 900 & 0.7356 & 0.1474 & 2110 & 0.477 & 54.44 \\
\hline
\end{tabular}



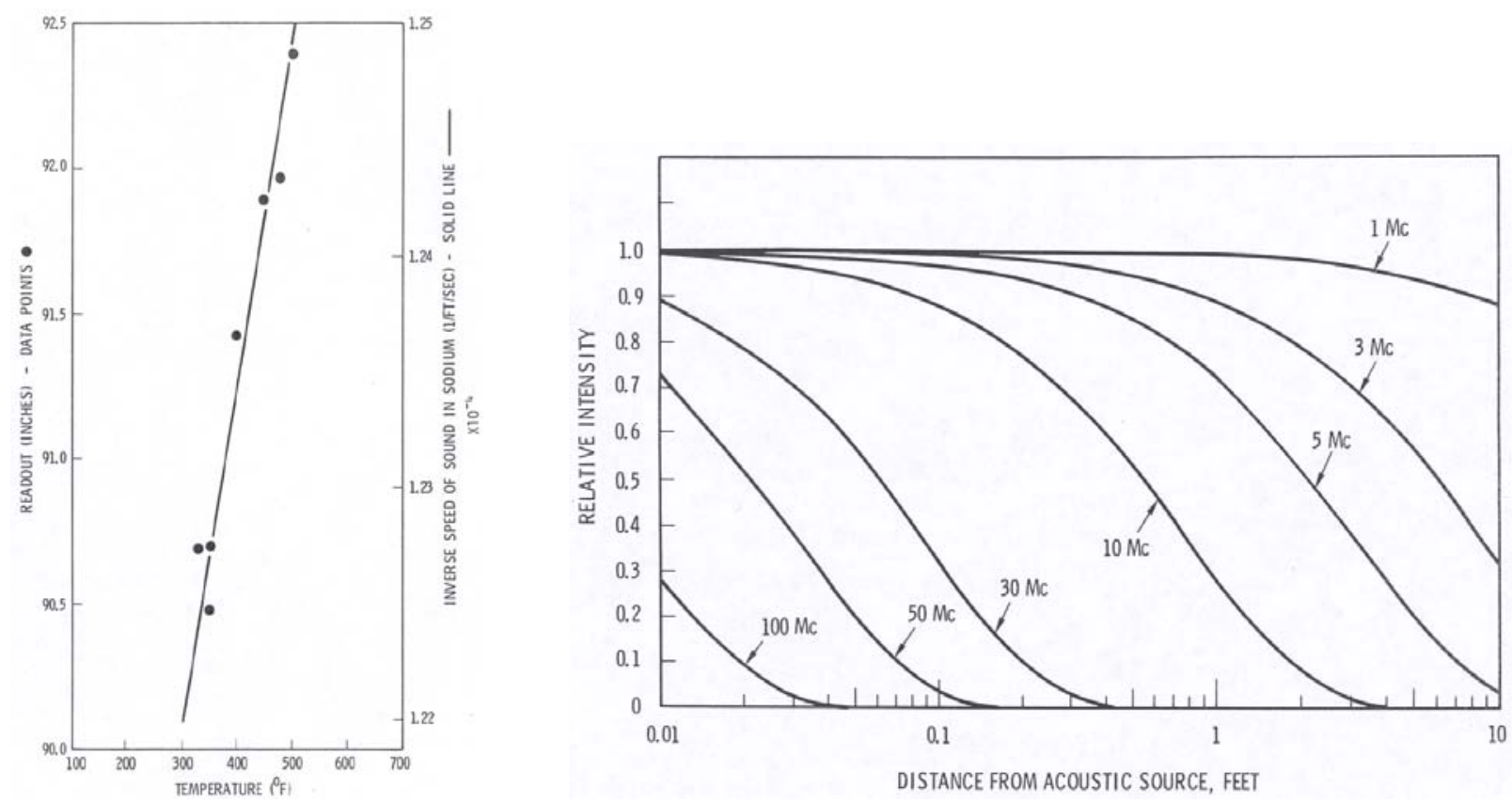

Figure 2.1. Acoustic Velocity and Attenuation in Liquid Sodium

(Boehmer et al. 1975; Ord and Smith 1972a)

Sodium's high-thermal conductivity, low-vapor pressure, and minor neutron moderation permit very high power densities in liquid metal-cooled reactors. But sodium use is not limited to reactor cooling applications. Of all the alkali metals, sodium has had perhaps the greatest commercial success, owing to its relative ease of manufacture and its important role worldwide in the manufacture of organolead compounds for use as gasoline octane enhancers. The decline of organoleads in North America has greatly affected U.S. production. Other sodium uses exist, but none requiring the massive quantities needed for lead antiknock compounds. However, sodium is used to make sodium methylate, herbicides, dyes, rubber, fragrances, vitamins, and ibuprophen. In metal manufacture, sodium is used in tantalum, titanium, silicon, refining metallic lead, and grain refining. Newer uses include sodium batteries, flue-gas cleanup, and alloy surface modification. Safe handling of sodium requires special consideration because of its high reactivity (Eggeman 2007).

\subsection{Additional Diagnostic Sensors for Fast Reactors}

A review of instrumentation, monitoring, and non-destructive evaluation systems for new fast reactors was recently published by Bond et al. (2007a). Applications of acoustic instrumentation have been reviewed by Lennox et al. (1993). Specific acoustic/ultrasonic sensor applications include (Hayes 1974; Hess and Ruppert 1975):

- Ultrasonic sodium temperature measurement

- Sodium level measurement (Boehmer and Smith 1976)

- Failed fuel element detection and location

- Sodium flow measurement (Eckert and Gerbeth 2002) 
- Search and retrieval guidance for misplaced or foreign objects

- Detection of sodium cavitation/boiling (Gavin and Anderson 1971; Nakamoto et al. 1984)

- Leak detection

- Water-sodium leaks in steam generators

- Structure-borne noise/loose-part detection.

Particular challenges are known to be faced when performing ultrasonic inspection in liquid sodium filled piping at elevated temperature (Mech and Martin 1982). HEDL conducted extensive laboratory studies using advanced signal processing methods to extract crack signals from stainless steel immersed in liquid sodium. With technology available in the mid-1970s, through-wall fatigue cracks became invisible when immersed in sodium. The historic data are limited (Bond et al. 2007b) but suggest a significant technical issue and the need for more work to fully understand the limits of ultrasonic inspection (NDT) when proposed for sodium-cooled reactor applications. To overcome this issue, unique NDT methods, such as the "delta mode conversion technique” (Cross 1967; Hannah 1968; Bond and Saffari 1984) may be required. 



\subsection{Testing Facilities for Under-Sodium Viewing Systems}

Development and evaluation of under-sodium viewing systems requires access to high-temperature liquid sodium. The High Temperature Sodium Facility at HEDL was used to test instrumentation destined for the core of the Fast Flux Test Facility in Richland, Washington. However, this facility was dismantled in the late 1970s.

Facilities still exist at the PNNL for laboratory-scale experiments with liquid sodium. In recent years, technical support and glovebox-scale laboratory testing has been provided to:

1. the FFTF, in support of sodium-cooling loop draining activities,

2. the U.S. DOE for evaluation of sodium disposal methods and for evaluation of new methods for treatment of sodium-bonded irradiated nuclear fuel,

3. local Hanford waste treatment contractors,

4. NASA contractors involved in sodium fuel cell research.

The PNNL sodium laboratory will be used for transducer wetting studies and limited under-sodium ultrasonic transducer evaluations during FY09.

Argonne National Laboratory activities have focused on evaluations of sodium-loop components for advanced fuel cycle research and development. Supercritical $\mathrm{CO}_{2}$ Brayton cycle power conversion is being considered as an advanced balance of plant technology. In this design, the component that provides the interface between the liquid sodium and supercritical $\mathrm{CO}_{2}$ is a compact heat exchanger known as a printed circuit heat exchanger (PCHE). This heat exchanger has very small coolant flow passages that may foul or plug depending upon sodium coolant conditions.

As shown schematically in Figure 3.1, the test apparatus consists of:

1. a main sodium loop including three test sections,

2. a bypass sodium loop including a cold trap/economizer assembly, and

3. an auxiliary system composed of Argon and vacuum lines.

Both the main and bypass loops are constructed from $1 / 2$-inch OD, 0.049-inch thick, type 316 stainless steal tubing. Other major components include three electromagnetic (EM) flow controllers (one each for the three test sections), two EM pumps (one for the main loop and one for the bypass loop), five EM flow meters, and expansion and dump tanks.

This apparatus is being used to investigate the possible plugging of narrow flow channels due to an impurity (e.g., oxides) present in the flowing sodium. 


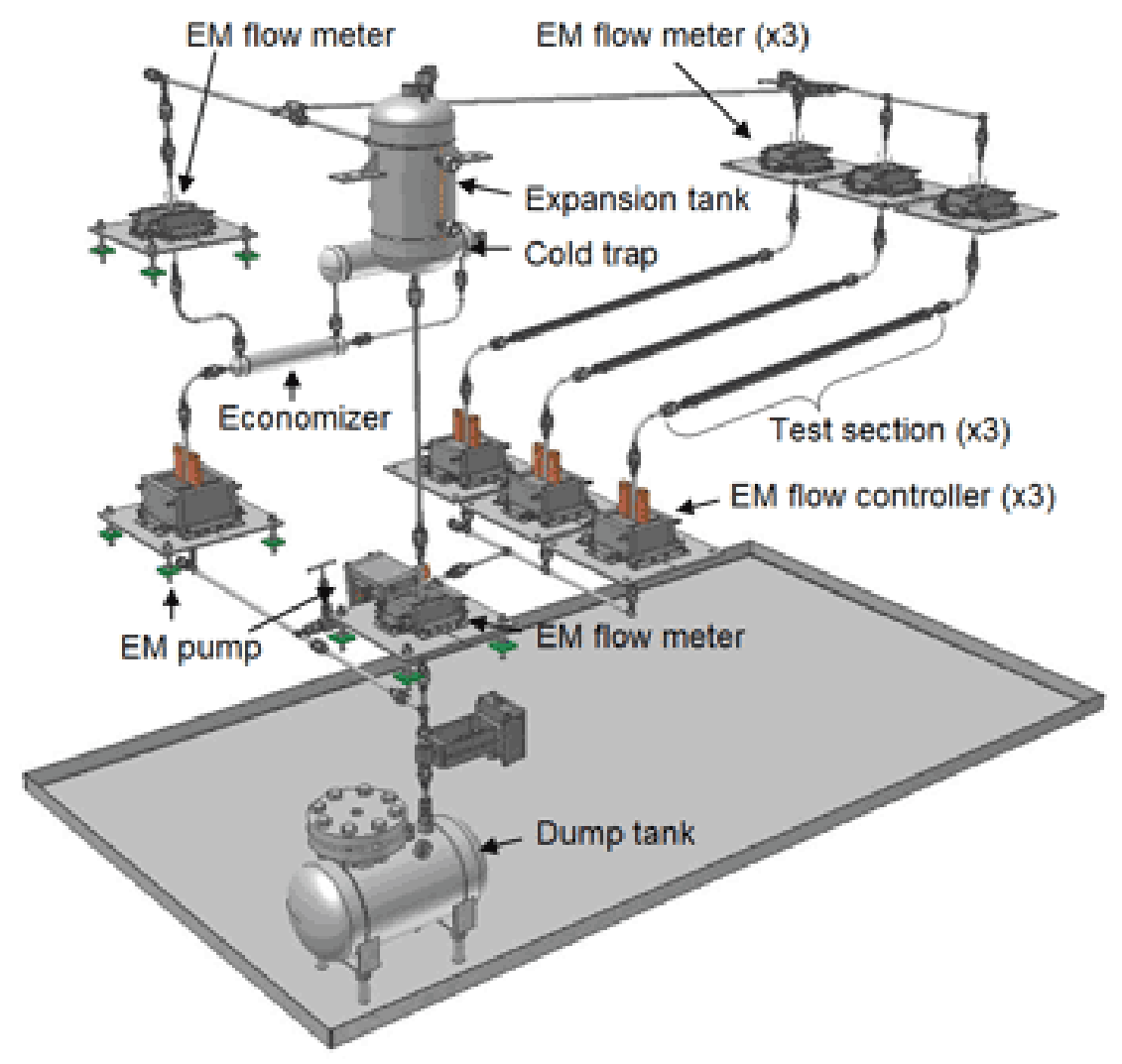

Figure 3.1. Sodium Plugging Test Facility at Argonne National Laboratory

ANL laboratory facilities available for large-scale, under-sodium testing are summarized below.

- Sodium Plugging Test Facility (ANL)

- Location: Building 370 Room C-1

- Activity: Small sodium loop for investigations of potential sodium plugging in printed heat exchanger channels.

- Sodium Scrubber Facility (ANL)

- Location: Building 308 Shop

- Activity: Onsite disposal of small quantities of sodium.

- Sodium Transfer Operations (ANL)

- Location: Building 206 High Bay and Annex that houses the Alkali Metal Passivation Booth

- Activity: Transfer sodium from the storage tank in the high bay of Building 206 into 1-gallon paint cans that Waste Management Operations (WMO) can accept for disposal.

- Sodium Loop for Steam Generation (ANL)

- Location: Building 308 High Bay 
- Activity: Pilot facility used to study heat exchange and steam generation efficiencies using sodium technology. The operation of the facility is currently suspended.

To support development and testing of under-sodium viewing systems developed in the current program, ANL staff have designed a Bench Scale USV Test Facility (BSTF) around the existing liquid sodium facilities summarized above. This facility will be used to evaluate ultrasonic waveguides and acquire under-sodium ultrasonic data during FY09. The modified BSTF is described below.

\subsection{USV Test System with Dump Tank}

This test system design offers the advantages of minimum $\mathrm{Na}_{2} \mathrm{O}$ contamination, easy sodium draining, flexible sodium level adjustment and safe storage of sodium. A schematic of this system appears in Figure 3.2. Both the sodium test vessel and the tank will be made of stainless steel Schedule 40 pipe. For single transducer/waveguide scan heads, two-dimensional rectangular scanning could be performed by moving the transducer inside the tank. If instead, the transducer remains stationary and the test target is translated, two-dimensional scanning could be performed with the translation hardware located either inside or outside the tank (the drawback being a larger required scanning area). The BSTF would also permit testing of array transducers.

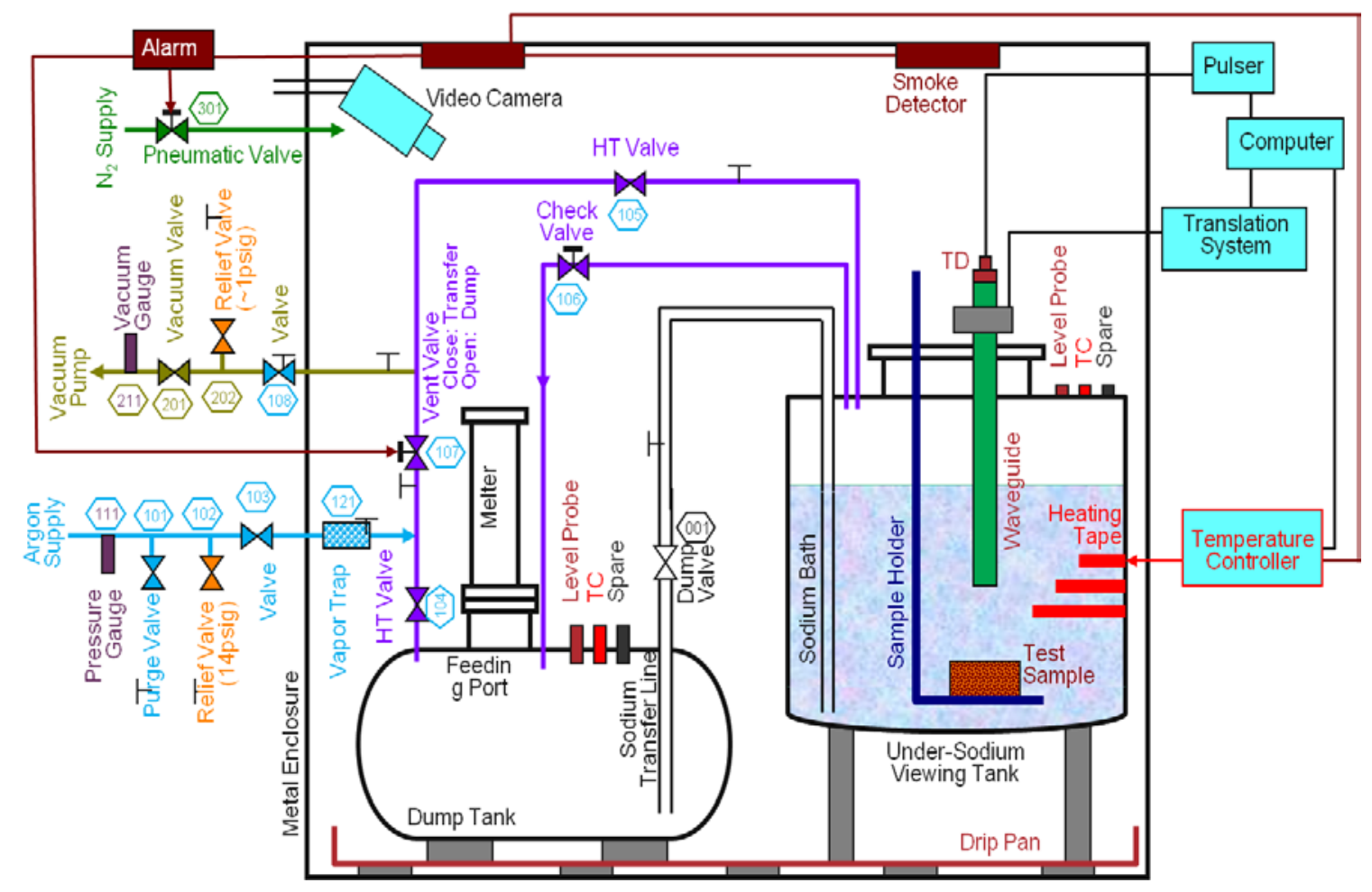

Figure 3.2. USV Test Tank with Sodium Dump Tank 



\subsection{Summary of International Research and Development Activities}

Over the past 30 years, a number of countries including Japan, India, Lithuania/Belgium, France, and Germany have pursued the development of ultrasonic ranging and/or imaging systems for liquid-metal cooled fast reactors (Taguchi et al. 1980; Hans et al. 1984; McKnight et al. 1984; McKnight 1988; Swaminathan et al. 1990; Wessels 1991; Lennox et al. 1993; Rajendran et al. 1996; Karasawa et al. 2000; Joo and Lee 2005; Kazys et al. 2005; Kazys et al. 2006; Kazys et al. 2007; Mazeika et al. 2007). An initial assessment of these activities is given in a paper by Bond et al. (2007b) and a more extensive review is provided below.

The mission of these systems is much the same as for the original U.S. FFTF, namely to inspect the reactor core region for foreign objects prior to refueling and to detect/assess component degradation or damage due to normal operation. A review of ultrasonic viewing systems for liquid-metal reactors was recently published by Jasiuniene (2007). A summary of imaging systems, transducer specifications, and operating parameters appears in Table 4.1.

In addition to imaging, there are wide-ranging studies of the use of acoustic and ultrasonic sensors for liquid metal-cooled reactors that include inspections (both active and passive - using acoustic emission and boiling detection) and other instrumentation including items such as flow meters (Bond 1988).

Activities by country are summarized below.

\subsection{Lithuania/Belgium}

(Kazys et al. 2005; Kazys et al. 2006; Kazys et al. 2007)

Development work has been performed jointly by the Belgian Nuclear Research Center SCK-CEN and the Ultrasound Institute at the University of Technology, Lithuania. Activities have focused on development of an ultrasonic imaging system for the Multi-purpose hYbrid Research Reactor for Hightech Applications (MYRRHA). This is an accelerator-driven sub-critical assembly cooled with a lead bismuth alloy. The single, scanned imaging sensor will operate in $\mathrm{Pb} / \mathrm{Bi}$ eutectic over a temperature range of $160-450^{\circ} \mathrm{C}$ with gamma radiation fields as high as $30 \mathrm{kGy} / \mathrm{h}$ and neutron fluxes up to $8.2 \times 10^{18}$ $\mathrm{n} / \mathrm{cm}^{2}$. Transducer materials under evaluation include $\mathrm{LiNbO}_{3}, \mathrm{GaPO}_{4}$, and aluminum nitride (AIN). Waveguide, unfocused, and focused transducer geometries have been evaluated. Transducer frequency is $5 \mathrm{MHz}$. A diamond-like carbon (DLC) layer interfaces the transducer to the molten metal. A photograph of the unfocused transducer assembly appears in Figure 4.1. 


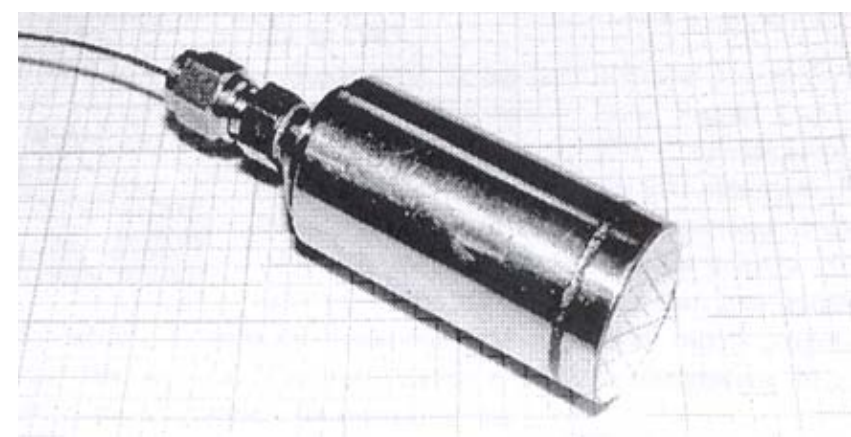

Figure 4.1. Single-Element Detector for Imaging in Pb-Bi Alloy (Kazys et al. 2006)

\subsection{United Kingdom}

(Barrett et al. 1984; McKnight et al. 1984; McKnight 1988; Lennox et al. 1993)

This work was a collaboration between the United Kingdom Atomic Energy Agency (UKAEA) and NNC Ltd., Engineering Development Centre, Risley. The 25-cm-diameter rotating linear transducer head was used to monitor the refueling process in the Prototype Fast Reactor in Dounreay, United Kingdom. In addition to eight downward-facing transducers, four additional side-mounted transducers provided detection of laterally located structures for collision avoidance. Transducer material is PZT operating at a frequency of $5 \mathrm{MHz}$ and temperatures up to $285^{\circ} \mathrm{C}$ in molten sodium. The transducer faceplate is a nickel diaphragm. A diagram of the imager head appears in Figure 4.2.

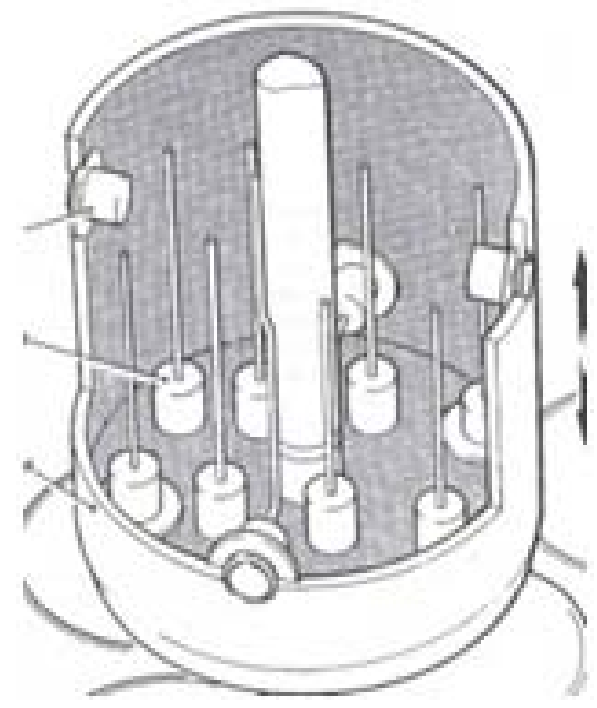

Figure 4.2. Linear Array Imager (side-mounted transducers are for positioning and obstacle avoidance) (McKnight et al. 1984) 
Table 4.1. Summary of Worldwide Research and Development in Under-Sodium Viewing

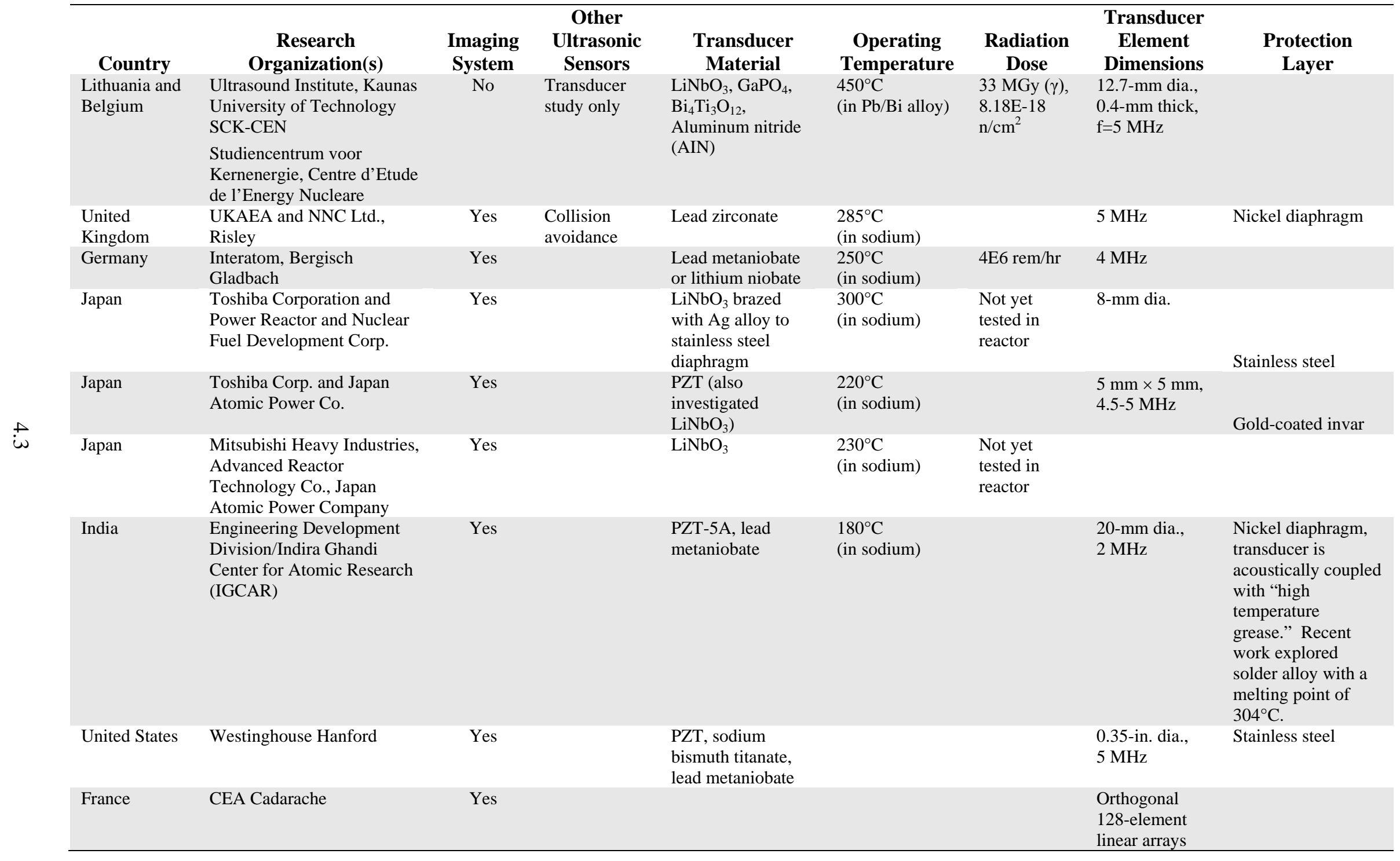


Table 4.1 (continued)

\begin{tabular}{|c|c|c|c|c|c|c|c|c|}
\hline Country & Backing & $\begin{array}{c}\text { Wetting } \\
\text { Interface }\end{array}$ & $\begin{array}{l}\text { Array Geometry } \\
\text { and Dimensions }\end{array}$ & $\begin{array}{l}\text { Pulser/ } \\
\text { Detector }\end{array}$ & $\begin{array}{l}\text { Tested in } \\
\text { Reactor? }\end{array}$ & $\begin{array}{l}\text { Image Data } \\
\text { Available? }\end{array}$ & $\begin{array}{l}\text { Date of Most } \\
\text { Recent } \\
\text { Publication }\end{array}$ & References \\
\hline $\begin{array}{l}\text { Lithuania and } \\
\text { Belgium }\end{array}$ & & $\begin{array}{l}\text { Diamond-like } \\
\text { carbon (DLC) }\end{array}$ & & & $\begin{array}{l}\text { Accelerator- } \\
\text { driven subcri- } \\
\text { tical assembly }\end{array}$ & & 2006 & $\begin{array}{l}\text { Kazys et al. 2005; } \\
\text { Kazys et al. 2006; } \\
\text { Kazys et al. 2007. }\end{array}$ \\
\hline $\begin{array}{l}\text { United } \\
\text { Kingdom }\end{array}$ & & & $\begin{array}{l}8 \text { transducers, two } \\
\text { rows of } 4\end{array}$ & & Yes & & 1984 & $\begin{array}{l}\text { Barrett et al. 1984; } \\
\text { McKnight et al. 1984; } \\
\text { McKnight 1988; } \\
\text { Lennox et al. 1993 }\end{array}$ \\
\hline Germany & & Gold & $\begin{array}{l}8 \text { transducers in a } \\
\text { paraboloid surround- } \\
\text { ing a single xmit-rcvr } \\
\text { transducer }(104 \mathrm{~mm} \times \\
104 \mathrm{~mm} \times 37.5 \mathrm{~mm}) \text {, } \\
\text { each transducer } \\
\text { equipped with lens }\end{array}$ & & Yes & Yes & 1984 & $\begin{array}{l}\text { Hans et al. 1984; } \\
\text { Wessels } 1991\end{array}$ \\
\hline Japan & $\begin{array}{l}\text { Stainless steel } \\
\text { back electrode }\end{array}$ & $\begin{array}{l}\text { Stainless steel } \\
\text { (would wet only } \\
\text { with flowing } \\
\text { sodium) }\end{array}$ & $\begin{array}{l}\text { Single, scanned } \\
\text { transducer }\end{array}$ & & $\begin{array}{l}\text { Tested in liquid } \\
\text { sodium }\end{array}$ & & 1997 & $\begin{array}{l}\text { Takeishi et al. 1997; } \\
\text { Karasawa et al. 2000; } \\
\text { Pro-Wave 2005; } \\
\text { Ando et al. } 2006\end{array}$ \\
\hline Japan & Ceramic & & $\begin{array}{l}36 \times 36 \text { elements in } \\
\text { a square array, } 9 \\
\text { blocks of } 12 \times 12\end{array}$ & & Yes & Yes & 2000 & \\
\hline Japan & $\begin{array}{l}\text { Thin stainless } \\
\text { steel plate }\end{array}$ & & 400 elements & & $\begin{array}{l}\text { Tested in liquid } \\
\text { sodium }\end{array}$ & & 1997 & \\
\hline India & Stainless steel & Polished nickel & $\begin{array}{l}\text { Single, scanned } \\
\text { transducer }\end{array}$ & $\begin{array}{l}\text { Commercial, } \\
\text { USIP-12 ultra- } \\
\text { sonic flaw } \\
\text { detector }\end{array}$ & Yes & Yes & 1990 & $\begin{array}{l}\text { Swaminathan et al. } \\
\text { 1990; Rajendran et al. } \\
1996\end{array}$ \\
\hline
\end{tabular}


Table 4.1 (continued)

\begin{tabular}{|c|c|c|c|c|c|c|c|c|}
\hline Country & Backing & $\begin{array}{c}\text { Wetting } \\
\text { Interface }\end{array}$ & $\begin{array}{l}\text { Array Geometry } \\
\text { and Dimensions }\end{array}$ & $\begin{array}{l}\text { Pulser/ } \\
\text { Detector }\end{array}$ & $\begin{array}{l}\text { Tested in } \\
\text { Reactor? }\end{array}$ & $\begin{array}{l}\text { Image Data } \\
\text { Available? }\end{array}$ & $\begin{array}{l}\text { Date of Most } \\
\text { Recent } \\
\text { Publication }\end{array}$ & References \\
\hline United States & & Gold & $\begin{array}{l}\text { Linear transducer } \\
\text { array, 0.35-in. dia. } \\
\text { transducers with a 2- } \\
\text { in. focal length lens }\end{array}$ & & $\begin{array}{l}\text { Tested in liquid } \\
\text { sodium }\end{array}$ & & 1975 & $\begin{array}{l}\text { Scott and Ying 1967; } \\
\text { Becker and Trantow } \\
\text { 1971; Ord and Smith } \\
\text { 1972a, b; Day and } \\
\text { Smith 1974a, b; Smith } \\
\text { et al. 1974; Boehmer } \\
\text { et al. 1975; Smith and } \\
\text { Day 1975; Boehmer } \\
\text { and Smith 1976; Bond } \\
\text { et al. 2007a) }\end{array}$ \\
\hline France & & & $\begin{array}{l}\text { IMARSOD, ortho- } \\
\text { gonal 128-element } \\
\text { linear arrays }\end{array}$ & & Tested in water & Yes & 2004 & $\begin{array}{l}\text { Imbert et al. } 1996 \\
\text { Baque } 2005\end{array}$ \\
\hline
\end{tabular}




\subsection{Germany}

(Hans et al. 1984; Wessels 1991)

This imaging system, developed at Interatom, Bergisch Gladbach, Germany incorporated eight lensfocused lithium niobate or lead metaniobate transducers in a paraboloid surrounding a single transmit/receive transducer. A photograph appears in Figure 4.3. The transducers operated at $4 \mathrm{MHz}$ in a liquid sodium temperature of $250^{\circ} \mathrm{C}$. A sacrificial gold coating provided the interface to the molten metal. A pair of these imaging systems (one upward looking and one downward looking) was deployed for in-service inspections of the SNR-300 reactor in Kalkar, Germany. Because this reactor was never fueled, there are no data on radiation effects.

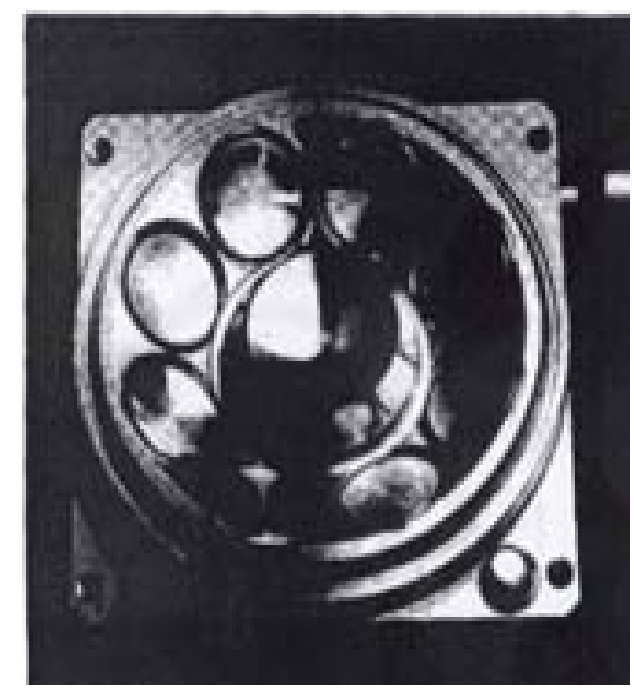

Figure 4.3. Parabolic Array Detector (Hans et al. 1984)

\subsection{Japan}

(Takeishi et al. 1997; Karasawa et al. 2000; Pro-Wave 2005; Ando et al. 2006)

Both single-transducer and transducer array work have been performed in Japan by Toshiba Corporation in collaboration with Japan Atomic Power Company. Photographs of the Toshiba singletransducer and transducer array appear in Figure 4.4 and Figure 4.5. The single-transducer uses a lithium niobate piezoelectric element brazed to a stainless steel diaphragm. The array imager consists of a $36 \times 36$ element matrix of square 5-mm $\times 5$-mm PZT transducers (arranged in nine blocks of $12 \times 12$ transducers each). The protective, sodium-wetting layer is gold-coated invar. Operational temperature is $220^{\circ} \mathrm{C}$ in sodium. 


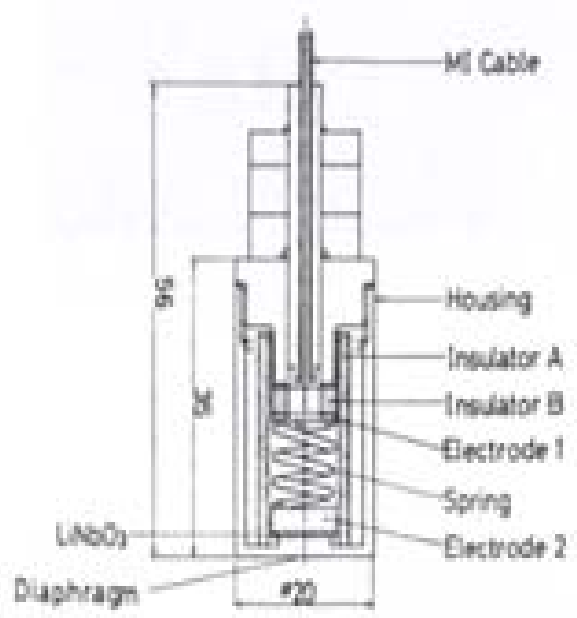

Figure 4.4. Toshiba Single-Element $\mathrm{LiNbO}_{3}$ Transducer (in collaboration with Power Reactor and Nuclear Fuel Development Corporation) (Taguchi et al. 1980)

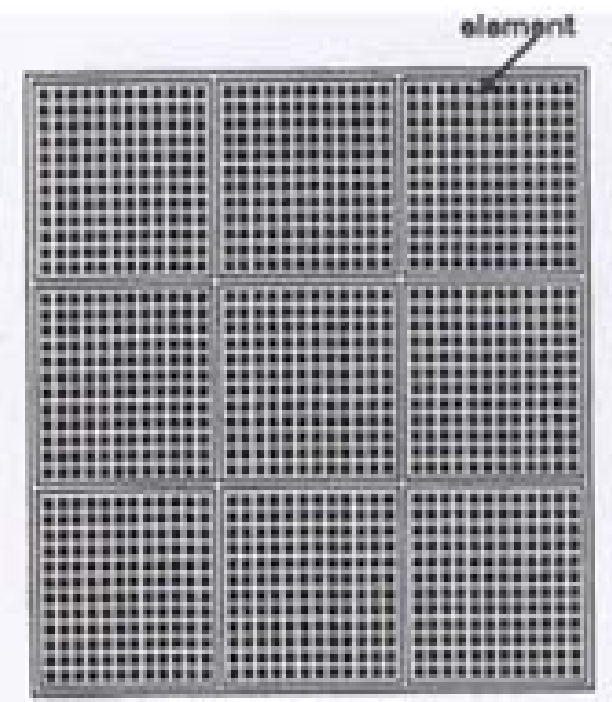

Figure 4.5. Toshiba $36 \times 36$ Element PZT Array Transducer (Karasawa et al. 2000)

Use of a two-dimensional array affords the opportunity to implement synthetic aperture focusing techniques (SAFT) for raster scanning with a minimal spot size due to the increased effective aperture. This imaging system has been commercialized by Toshiba (Matrixeye ${ }^{\mathrm{TM}}$ ) for use in airframe NDE of carbon fiber reinforced plastics.

Mitsubishi Heavy Industries has developed a 400-element 2-D imaging array detector using lithium niobate transducer elements. A photograph of one of the array subassemblies (20 transducers) appears in Figure 4.6. 


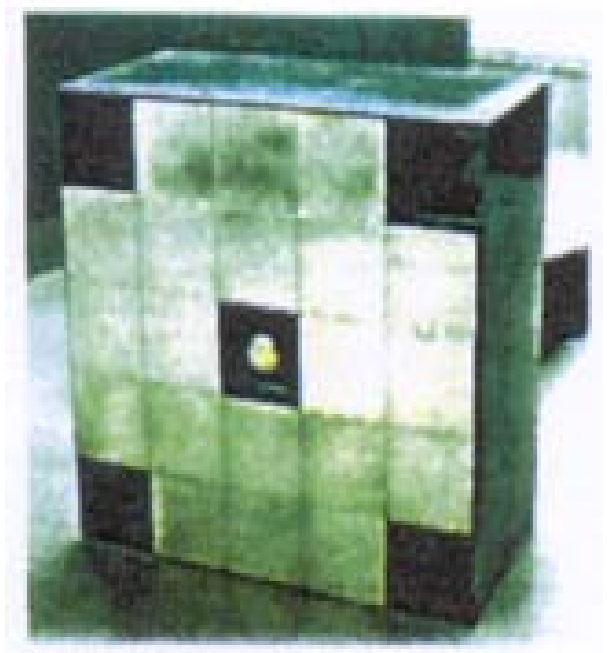

Figure 4.6. Mitsubishi Imaging Array Subassembly (20 elements) (Pro-Wave 2005)

\subsection{India}

(Swaminathan et al. 1990; Rajendran et al. 1996)

Extensive instrumentation development for FBRs has been performed largely within the Engineering Development Division of the Indira Ghandi Center for Atomic Research (IGCAR) at Kalpakkam. The under-sodium imager implemented at the Fast Breeder Test Reactor is a single-element, scanning device using PZT-5A or lead metaniobate transducer material. A schematic of the transducer assembly appears in Figure 4.7. The transducer is $20 \mathrm{~mm}$ in diameter and operates at $2 \mathrm{MHz}$. A polished nickel diaphragm interfaces the transducer to the molten sodium. Operating temperature is nominally $180^{\circ} \mathrm{C}$. A commercial ultrasonic flaw detector is used to send and receive ultrasonic pulses.

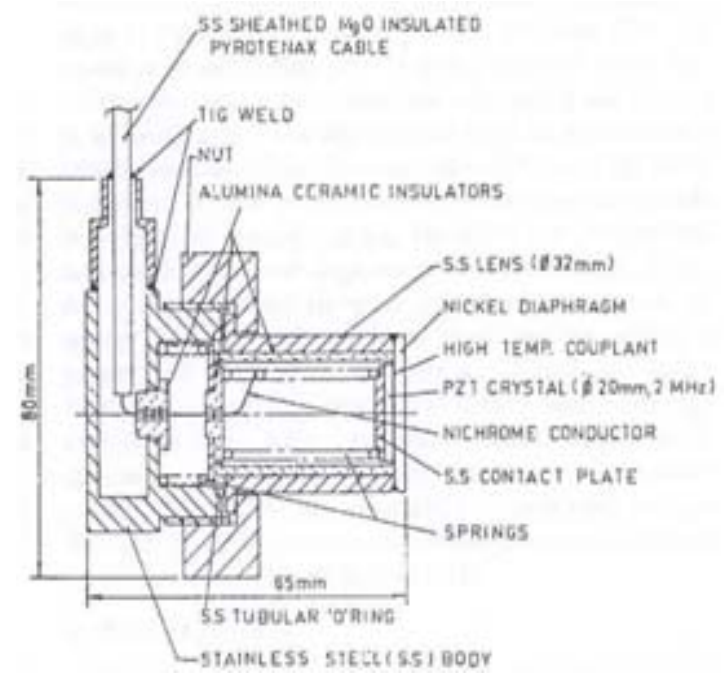

Figure 4.7. Scanned, Single-Transducer Assembly Tested in the Indian Fast Breeder Test (Swaminathan et al. 1990) 


\subsection{United States}

(Scott and Ying 1967; Becker and Trantow 1971; Ord and Smith 1972a, b; Day and Smith 1974a, b; Smith et al. 1974; Boehmer et al. 1975; Smith and Day 1975a; Boehmer and Smith 1976; Bond et al. 2007b)

Under-sodium imager development was conducted at HEDL, U.S. Department of Energy (DOE; then the Atomic Energy Agency) in Richland, Washington, in the 1970s. This imager was destined for deployment at DOE's Fast Flux Test Facility, a prototype liquid-metal-cooled fast reactor. It was also intended for use at the Clinch River Breeder Reactor to be built in Oak Ridge, Tennessee. A schematic of the transducer geometry and a photograph of the scanning head appear in (Ord and Smith 1972a). Threedimensional images were acquired by rotating the linear array through an arc and using time-of-flight data to derive the depth dimension. A variety of transducer materials were evaluated including PZT, sodium bismuth titanate, and lead metaniobate. Transducer diameter was 0.35 -in. with operating frequency of $5 \mathrm{MHz}$. A sacrificial gold layer provided the interface to the liquid sodium.
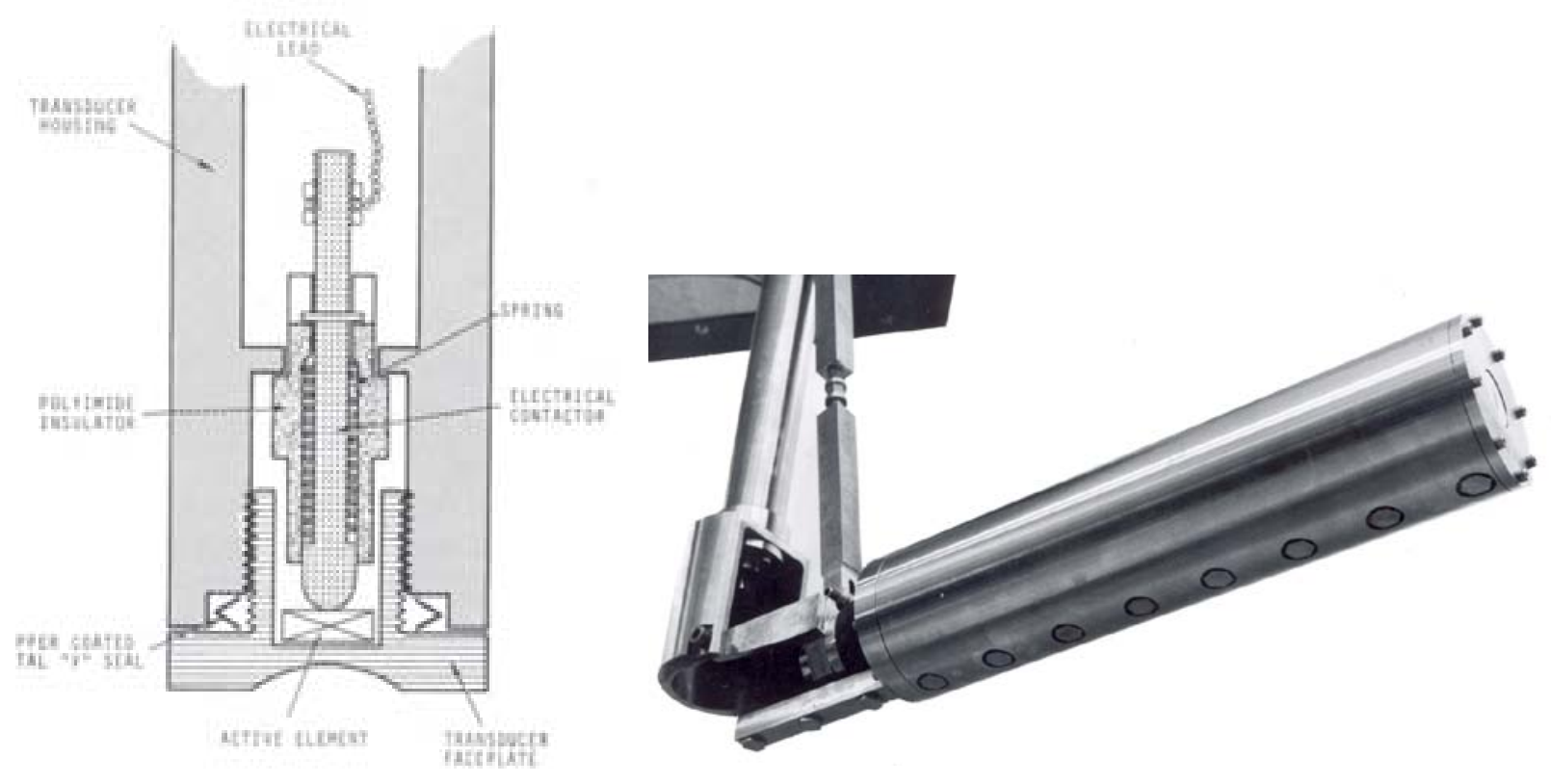

Figure 4.8. Transducer Assembly and Scanning Array (with 8 transducers) Designed for the Fast Flux Test Facility (Ord and Smith 1972a)

The HEDL group also developed ultrasonic sensors for measurement of sodium liquid level (Boehmer and Smith 1976). The level sensing system was tested in liquid sodium prior to its use in the Ex-Vessel Transfer Machine (EVTM)/Closed-Loop Ex-Vessel Machine (CLEM) cold wall heat removal tests for the Clinch River Breeder Reactor. 


\subsection{France}

(Imbert et al. 1996; Baque 2005)

French development of ultrasonic detection and imaging techniques was in support of inspections of the Phenix and Superphenix liquid metal FBRs. The "VISUS" system was a non-imaging ultrasonic system used to detect and locate possible obstacles preventing the rotating plugs from functioning during handling operations in Phenix (above the sodium level) (Cheeke 2002). A more sophisticated, linear SAFT system, "IMARSOD," was designed for use in Superphenix but has only been tested in water. The system consists of two orthogonal 128-element linear arrays operating at 1.6 MHz. One array, oriented vertically, transmits a fan-shaped beam along a given elevation angle and focused at a specific distance. The second array, oriented horizontally, receives an identical beam deflected by a given azimuth and focused at several distances or focal zones. A schematic of the system appears in Figure 4.9.

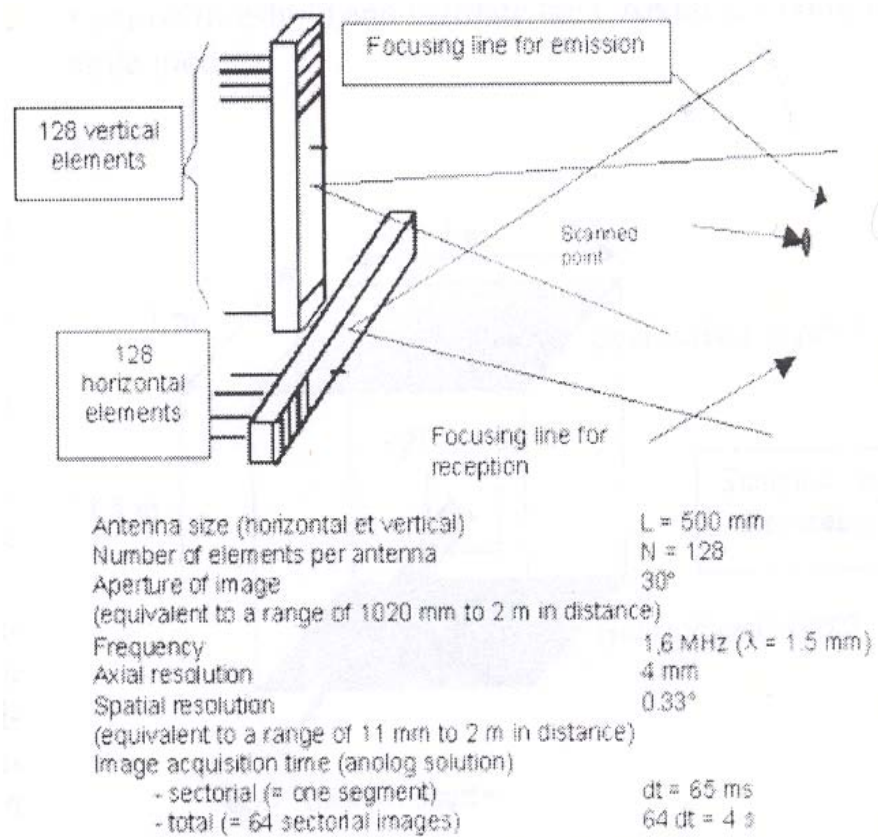

Figure 4.9. Beam-forming System for Ultrasonic Scanning Using Orthogonal Linear Arrays (Baque 2005) 


\subsection{Design Considerations for Under-Sodium Viewing Systems}

\subsection{Imager Geometries}

The ultrasonic imager footprint must comply with the available space and motion constraints of the specific reactor vessel. These constraints vary widely among existing metal-cooled fast reactor designs where, in general, no accommodation was made for an imager during the design process. Ideally, the reactor core design should provide sufficient clear space for the imager and acoustic beam to access all regions of interest during maintenance inspections. Likewise, provision should be made for above-core stowage of the imager where it can be shielded from radiation and temperature extremes. The technology review has revealed three general imager geometries including single-transducer, linear array, and twodimensional array. These are summarized in Figure 5.1. For the case of the single, spatially scanned transducer, a right angle reflector is sometimes used to permit azimuthal scanning.

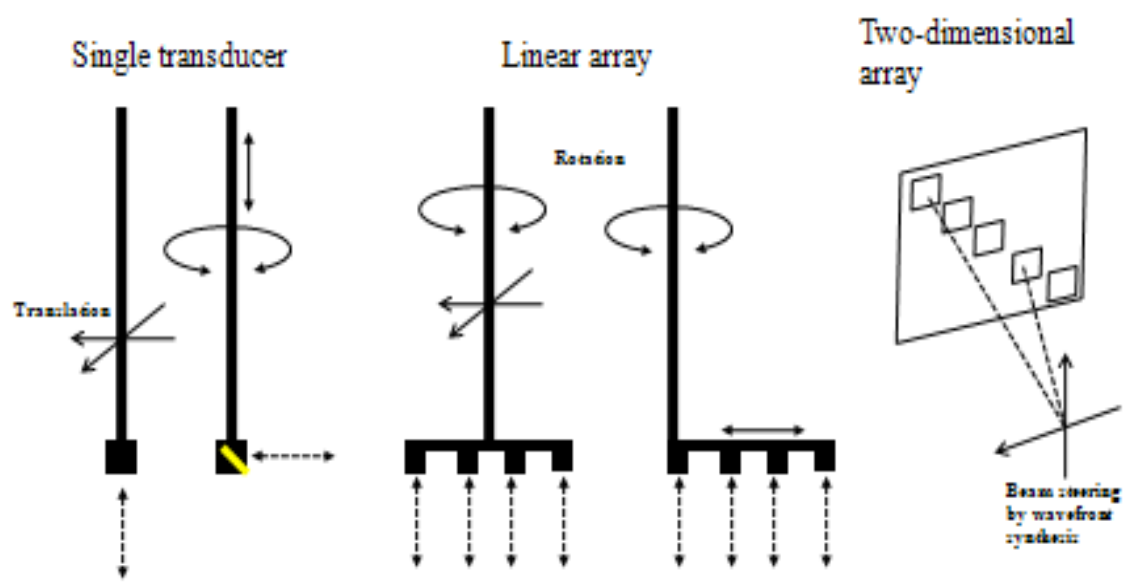

Figure 5.1. Ultrasonic Imager Configurations

Note that, in addition to the ultrasonic transducers used for imaging, supplemental transducers are frequently required for positioning the camera and for collision avoidance. The specifications (size, operating frequency, etc.) for these two types of transducers often differ even within a single camera system (Ord and Smith 1972a; McKnight et al. 1984).

\subsection{Spatial Resolution}

For scanned ultrasonic sensors, lateral image resolution is largely determined by:

1. operating frequency (usually the mechanical resonance frequency of the piston-mode piezoelectric transducer); 
2. wavelength of the longitudinal wave in the working fluid (determined by the transducer operating frequency and the velocity of ultrasound in the working fluid (in this case, sodium); and

3. the spatial increment (e.g., $\Delta \mathrm{x}$ and $\Delta \mathrm{y}$ ) of the transducer scanning system.

Range resolution is determined by the transducer pulse width which is limited by the mechanical ringdown time of the piezoelectric transducer (Bond and Saffari 1984).

Representative calculations are summarized in Figure 5.2 for the transducer used in the HEDL undersodium imaging system. Note that for a $5-\mathrm{MHz}$ transducer and a sodium sonic velocity of $2.45 \times$ $10^{3} \mathrm{~m} / \mathrm{sec}$, the longitudinal wavelength in sodium is $0.5 \mathrm{~mm}$. In the absence of a focusing lens, ultrasonic imaging measurements are generally made within the Fresnel- or near-field distance of the transducer where the beam diameter is smallest. At the Fresnel distance, the acoustic beam diameter is approximately equal to the transducer diameter. For a 0.5-in.-diameter transducer operating at $5 \mathrm{MHz}$, the Fresnel distance in liquid sodium is $8.2 \mathrm{~cm}$ or $3.2 \mathrm{in}$.

In liquid sodium at a temperature of $250 \mathrm{C}$, sound velocity is $2.45 \times 10^{3} \mathrm{~m} / \mathrm{sec}$ [1]. Hence, the wavelength of a longitudinal wave of frequency, ? $=5 \mathrm{MHz}$, is

$$
\lambda=\frac{C}{v}=0.5 \mathrm{~mm}
$$

The Fresnel- or near-field distance, $Z_{F}$, for a circular, flat transducer moving in piston mode is given by

$$
Z_{F}=\frac{a^{2}}{\lambda} \quad \text { where } a \text { is the transducer radius }
$$

For a transducer diameter of $0.5^{\prime \prime}(a=0.64 \mathrm{~cm})$ the Fresnel distance is $8.19 \mathrm{~cm}$

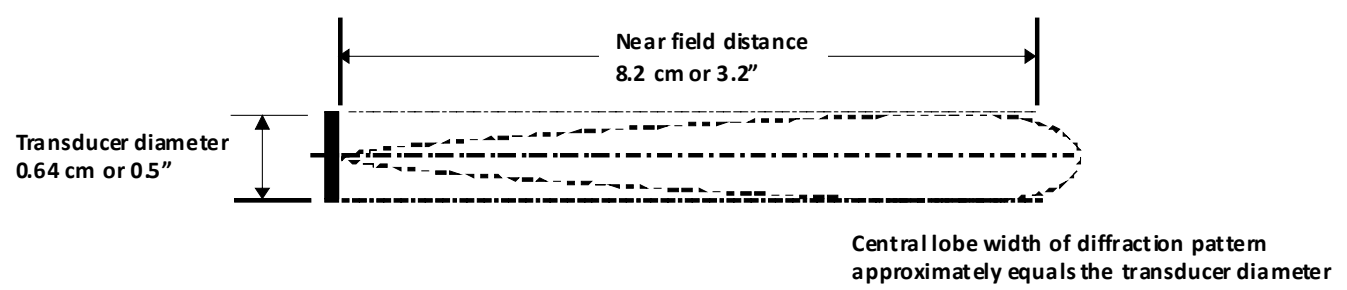

Figure 5.2. Transducer Beamwidth Calculations for Liquid Sodium

A typical ultrasonic pulse waveform for a 5-MHz, piston-mode transducer appears in Figure 5.3. The left waveform is the detected ultrasonic reflection signal from a downrange glass plate. The right image is the Fourier transform of this signal indicating the mechanical bandwidth of the piezoelectric transducer. 

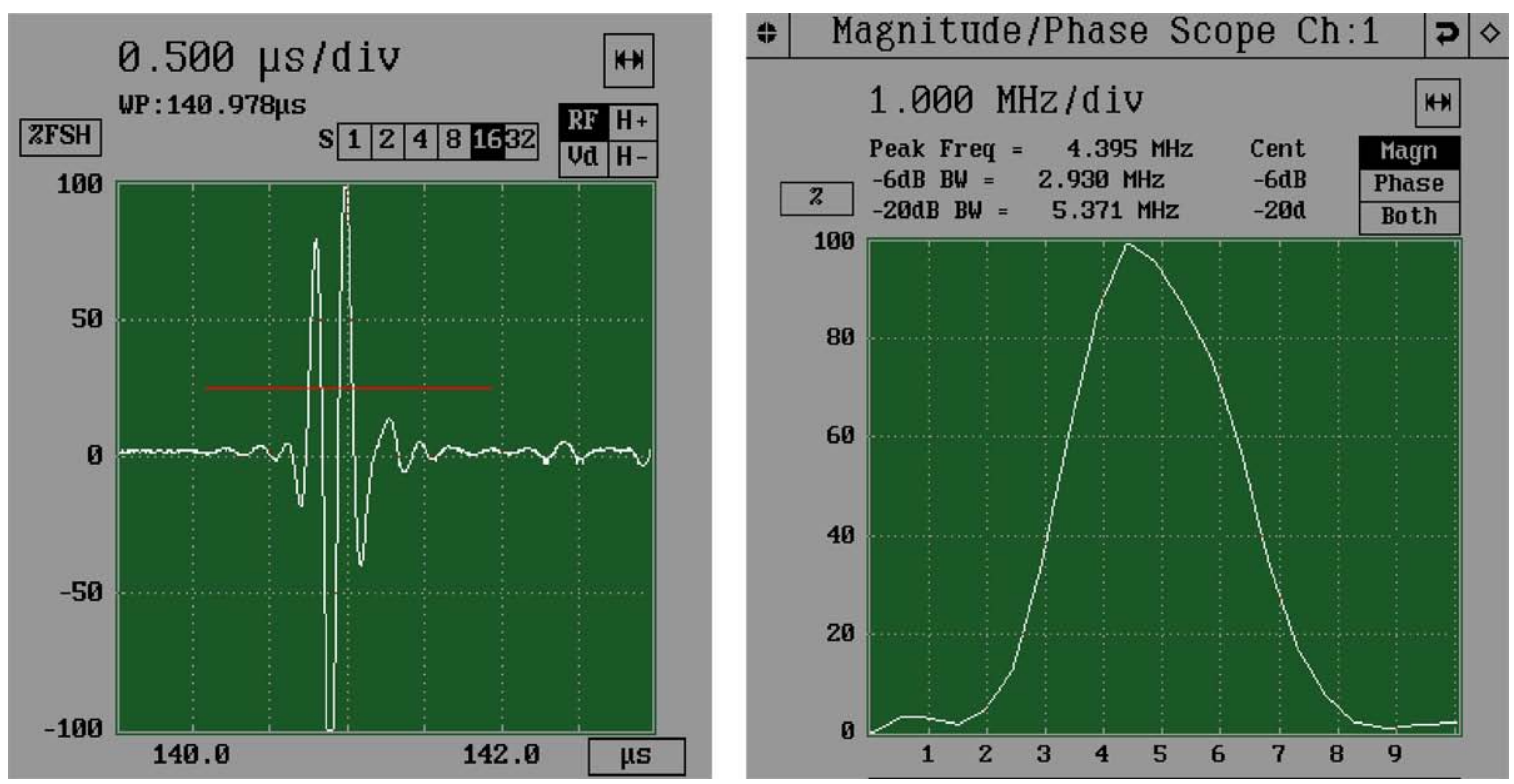

Figure 5.3. Transducer Pulse Properties (Panametrics lead metaniobate, 3/4-in.-dia., 3-in. focus in water, design frequency $=5 \mathrm{MHz}$; PNNL data)

This transducer was fixtured in an $\mathrm{X}-\mathrm{Y}$ translation stage and used to acquire the ultrasonic image of the machined stainless steel plate shown in Figure 5.4 and Figure 5.5. Scanner lateral resolution was 0.010 in. in both directions. Pulse width was $1.0 \mu \mathrm{sec}$. The milled letters were imaged through the back side of the plate.

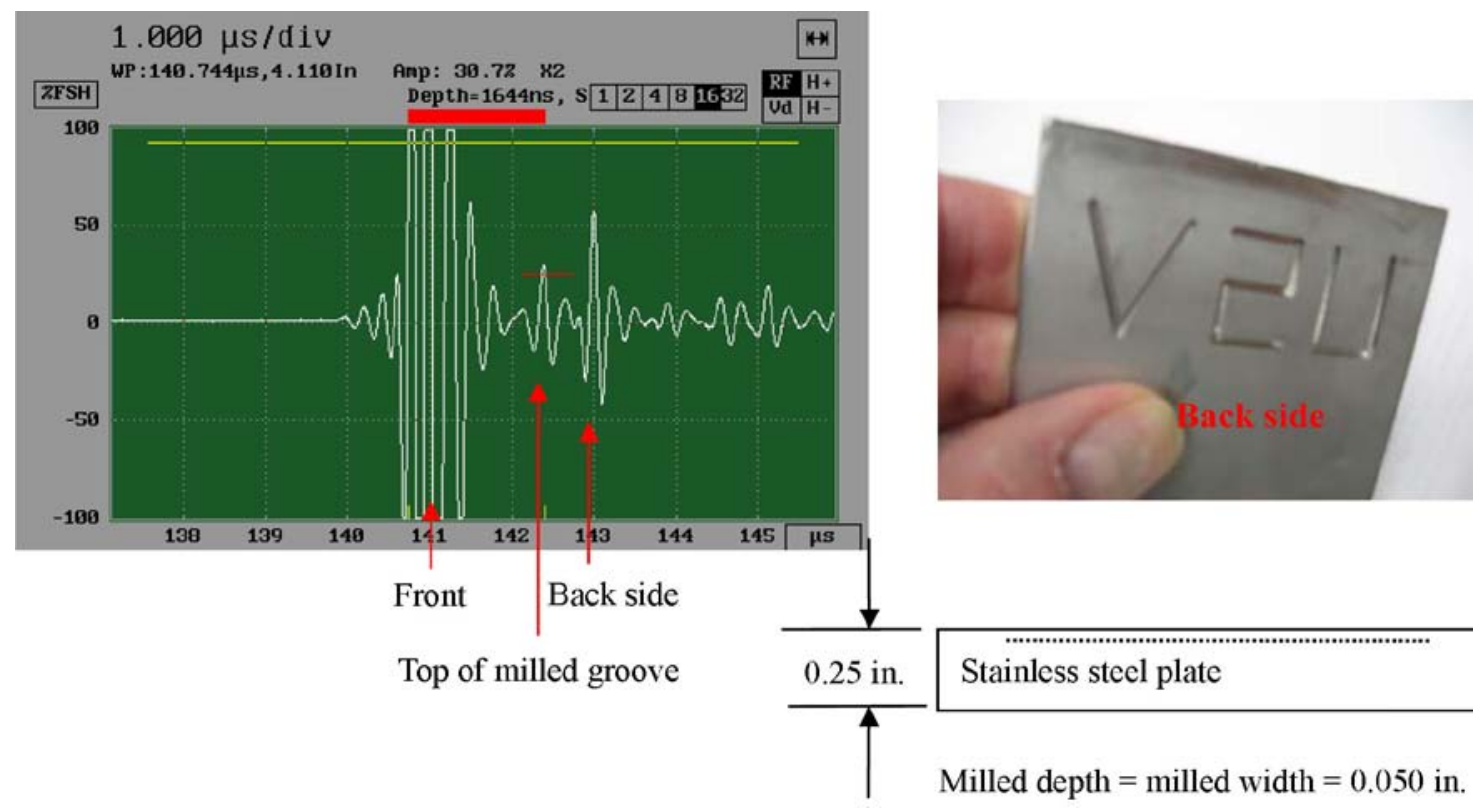

Figure 5.4. Ultrasonic Reflections from Stainless Steel Plate with Milled Letters. The letters were imaged through the front side of the plate (PNNL data). 


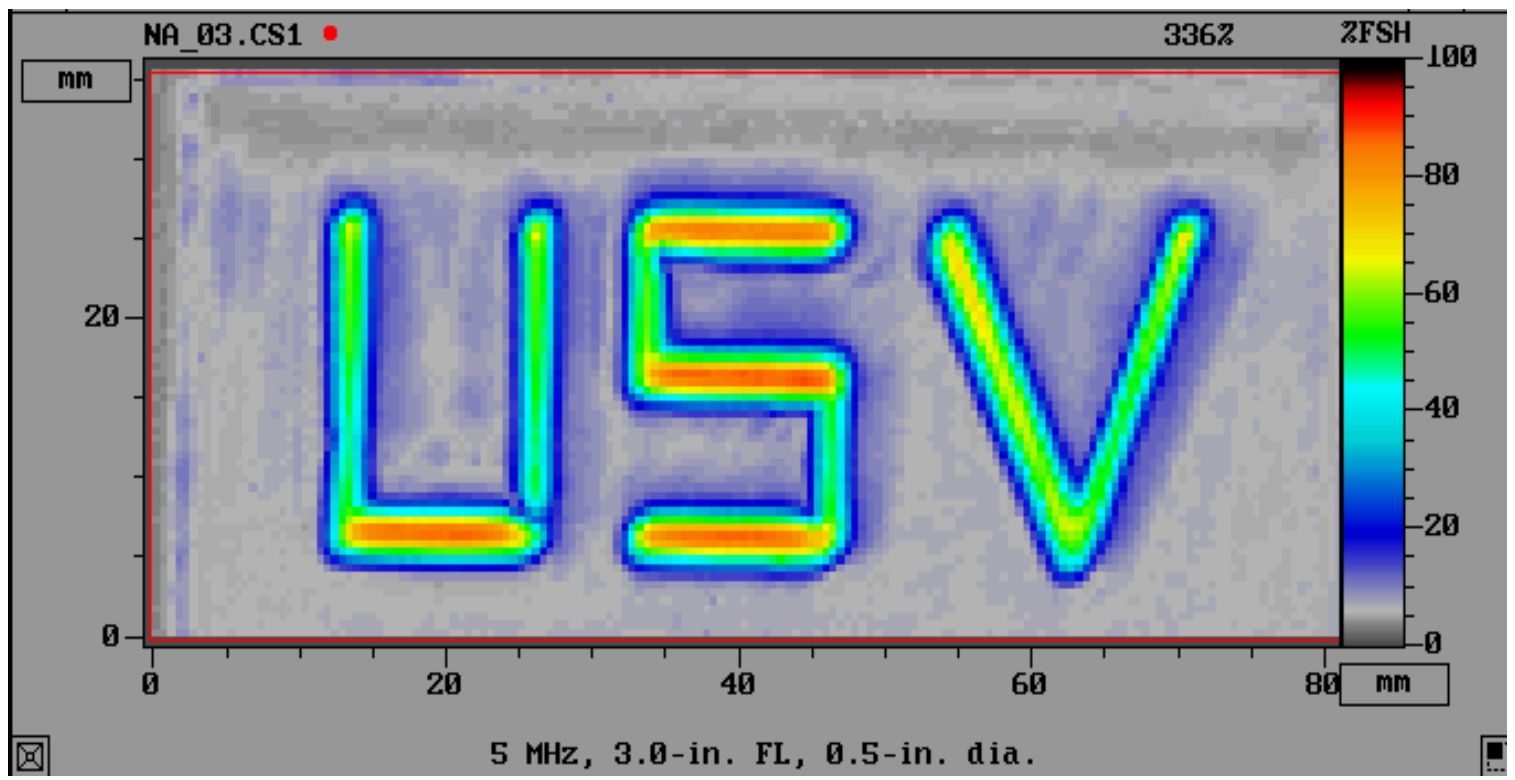

Figure 5.5. Ultrasonic Image of Letters Milled into Back Surface of Stainless Steel Plate. The imaging tank fluid is water. Scanner resolution $=0.010$ in., transducer frequency $=5 \mathrm{MHz}$, pulse width $=1.0 \mu$ sec (PNNL data). 


\subsection{Transducer Assembly}

Transducer assemblies destined for under-sodium applications that have been fabricated to date and for which details are published are remarkably similar in design. A generic schematic diagram summarizing the assembly components and interfaces is shown in Figure 6.1.

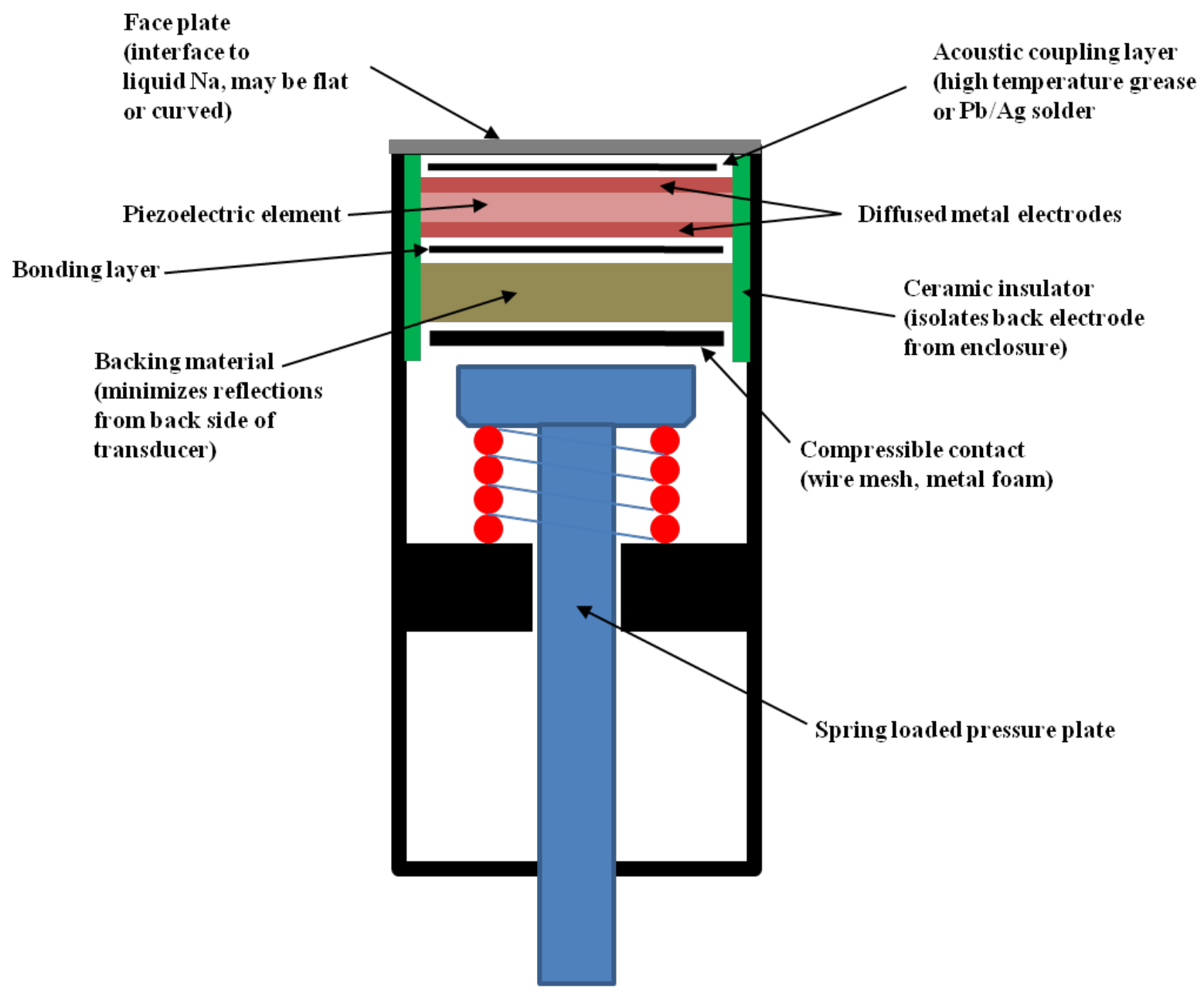

Figure 6.1. Transducer Assembly Designed for Under-Sodium Viewing

Very careful consideration must be given to each layer of the assembly. These considerations are summarized below.

\section{Faceplate}

The transducer faceplate couples acoustic energy to and from the surrounding sodium. The faceplate is bonded to and moves in unison with the front face of the ultrasonic transducer. In some applications, the faceplate is curved in order to focus the acoustic energy to a spot with minimum lateral dimensions. In others, the faceplate is flat and the central lobe of the near-field diffraction 
pattern determines the spot size and thus the lateral resolution of the transducer. Of special importance is the material from which the faceplate is made. The material must be wetable by liquid sodium to exclude gas layers and permit maximum acoustic coupling. To this end, a variety of faceplate and/or faceplate coating materials have been investigated including polished nickel (Taguchi et al. 1980), diamond-like carbon (used for lead bismuth cooled reactors) (Kazys et al. 2006), gold-coated invar (McKnight 1988), and thermally etched stainless steel with a 1-micron sacrificial coating of gold (Day and Smith 1974a). Thermal etching of the stainless steel in vacuum appears necessary to remove the thin layer of $\mathrm{CrO}$ on stainless steel that prevents wetting. It may also be possible to remove the $\mathrm{CrO}$ coating if the molten sodium is agitated or made to impinge on the stainless steel (Ono et al. 2006). In general, stainless steels commonly used in SFR reactors (e.g., 304 stainless steel) do not wet well in stagnant sodium.

\section{Faceplate-transducer coupling layer}

The faceplate linear thermal expansion coefficient must be closely matched to that of the transducer material to avoid inducing excessive internal stresses and cracking of the transducer. In practice, exact matching of the thermal expansion coefficients is difficult to achieve. Instead, an intermediate, ductile layer is fabricated between the back side of the transducer faceplate and the front side of the acoustic transducer. High-temperature grease (Taguchi et al. 1980) and various silver solder alloys (Day and Smith 1974a; Ono et al. 2006) have been used for this purpose. There is a special appeal to the use of non-metallic compounds (e.g., high viscosity greases) for this layer. The ductility of a high-temperature grease will minimize thermally induced shear stresses in the transducer face. If a tin-alloy solder is utilized, it may interact with (e.g., dissolve) the transducer front face electrode (often a diffused layer of silver) and degrade the electrical connection (Day and Smith 1974a). The low ductility of tin-alloy solders can also precipitate cracking of the transducer due to thermal shock.

\section{Transducer electrodes}

For single-crystal transducers (e.g., $\mathrm{LiNbO}_{3}$ ), electrodes are typically evaporated or sputtered onto the front and back faces. These conductive coatings are generally stable even at high temperatures. For piezoelectric ceramics (e.g., PZT), the electrodes are usually diffused into the faces during the sintering process or in a separate lower-temperature operation. When such a sensor is placed in a high-temperature operating environment, the conductive electrode material may diffuse further into the piezoelectric ceramic or be drawn from the ceramic through absorption or capillary action into an adjacent layer. HEDL USV developers found it necessary to replace the diffused silver transducer electrodes with evaporated copper or platinum (Day and Smith 1974a).

\section{Piezoelectric transducer element}

Transducer elements that can operate in hostile environments, specifically those encountered in fast liquid-metal cooled reactors have been under investigation for many years. A comprehensive review is given in a report by Broomfield (1985) and in shorter form in a journal paper (Broomfield 1980).

A summary of commercially available high-temperature transducer materials and their electrical/ mechanical properties appears in Table 6.1. An excellent review of high-temperature piezoelectric transducer materials suitable for ultrasonic viewing in liquid metals appears in the paper by Kazys et al. (2008). An options matrix to aid transducer selection appears in Table 6.2. 
Table 6.1. Properties of Selected High-Temperature Piezoelectric Transducers

\begin{tabular}{|c|c|c|c|c|c|c|c|c|c|}
\hline Material & $\begin{array}{c}\text { Frequency } \\
\text { Constants, } \\
\text { mm/MHz }\end{array}$ & $\begin{array}{l}\text { Dielectric } \\
\text { Constants }\end{array}$ & $\begin{array}{c}\mathbf{d}_{33} \\
\text { Coefficient, } \\
\text { m/V (-12) }\end{array}$ & $\begin{array}{c}\mathbf{G}_{33} \\
\text { Coefficient, } \\
\text { Vm/N (-3) }\end{array}$ & $\begin{array}{l}\text { Coupling } \\
\text { Factor, } \\
\mathbf{k}_{33}(\%)\end{array}$ & $\begin{array}{c}\text { Maximum } \\
\text { Temperature, } \\
\text { Degrees C }\end{array}$ & $\begin{array}{c}\text { Mechanical, } \\
\text { Q }\end{array}$ & $\begin{array}{c}\mathbf{K}_{\mathrm{p}} \text { Planar } \\
\text { Coupling } \\
\text { Coefficient }\end{array}$ & $\begin{array}{c}\text { Acoustic } \\
\text { Impedance, } \\
\mathrm{gm} / \mathrm{cm}^{2} \mathrm{~s}\end{array}$ \\
\hline Quartz & 2.87 & 4.5 & 2 & 50 & 11 & 550 & 10,000 & --- & 15 \\
\hline $\begin{array}{l}\text { Lithium Niobate, } \\
\text { Y-Cut }\end{array}$ & 3.68 & 30 & 6 & 23 & 15 & 1000 & --- & --- & 32 \\
\hline PZT-4 & 2.0 & 1300 & 15.5 & 26 & 70 & 328 & 500 & 0.58 & 30 \\
\hline $\begin{array}{l}\text { PZT-5A } \\
\text { Lead Zirconate Titinate }\end{array}$ & 1.88 & 1700 & 375 & 25 & 70 & 365 & 75 & 0.6 & 29 \\
\hline $\begin{array}{l}\text { K-81 } \\
\text { Lead Niobate }\end{array}$ & 1.65 & 300 & 85 & 32 & 40 & 400 & 15 & 0.1 & 20 \\
\hline $\begin{array}{l}\text { K-12 } \\
\text { Bismuth Titinate }\end{array}$ & 2.25 & 145 & 12 & 9.5 & 12 & 820 & 200 & 0.07 & 28.5 \\
\hline $\begin{array}{l}\text { K-15 } \\
\text { Bismuth Titinate }\end{array}$ & 2.0 & 130 & 18 & 10 & & 600 & 100 & & $\leq 29$ \\
\hline $\begin{array}{l}\text { Tourmaline } \\
\text { Z-Cut }\end{array}$ & 7.1 & & 1.8 & & & 1800 & & & \\
\hline Nova 3B & 2.18 & 215 & 80 & 55 & 51 & 350 & 40 & 0.01 & 33 \\
\hline
\end{tabular}


Table 6.2. Matrix Options

\begin{tabular}{|c|c|c|c|}
\hline \multicolumn{4}{|c|}{ Ultrasonic Transducer for Under Sodium Viewing - Materials Options Matrix } \\
\hline Component & Material & $\begin{array}{c}\text { Advantages } \\
\end{array}$ & Disadvantages \\
\hline \multirow{8}{*}{$\begin{array}{l}\text { Transducer faceplate } \\
\text { or faceplate coating }\end{array}$} & Invar & $\begin{array}{l}\text { Coefficient of thermal expansion (CTE) same as piezoelectric ceramic. CTE } \\
\text { can be adjusted by the amount of nickel in the invar. }\end{array}$ & \\
\hline & Nickel & May wet in liquid sodium. CTE matches lithium niobate. & \\
\hline & Stainless steel & $\begin{array}{l}\text { Frequently used. May wet in flowing sodium. Slow wetting in stagnant } \\
\text { sodium. }\end{array}$ & $\begin{array}{l}\text { Will not wet in stagnant sodium } \\
\text { unless gold-coated. }\end{array}$ \\
\hline & Titanium & CTE matches bismuth titanate. & $\begin{array}{l}\text { Very expensive. Doubtful } \\
\text { sodium wetting. }\end{array}$ \\
\hline & Glass & $\begin{array}{l}\text { Acts as thermal barrier to protect piezoelectric element from thermal shock. } \\
\text { CTE close to piezo ceramics. }\end{array}$ & $\begin{array}{l}\text { No published data on this } \\
\text { material. }\end{array}$ \\
\hline & $\begin{array}{l}\text { Diamond-like } \\
\text { carbon }\end{array}$ & $\begin{array}{l}\text { Demonstrated in lead-bismuth eutectic up to } 450^{\circ} \mathrm{C} \text { (Kazys et al. 2005; Kazys } \\
\text { et al. 2006; Kazys et al. 2007). }\end{array}$ & No data for liquid sodium. \\
\hline & Gold coating & Known to facilitate wetting in liquid sodium (Smith and Day 1975b). & $\begin{array}{l}\text { Sacrificial layer; requires } \\
\text { recoating. }\end{array}$ \\
\hline & $\begin{array}{l}\text { Alloy } 52 \\
\text { (nickel-iron) }\end{array}$ & CTE matches bismuth titanate. & \\
\hline \multirow{6}{*}{ Piezoelectric element } & PZT-5A & Common material, 70\% coupling efficiency. & Max. temp. only $360^{\circ} \mathrm{C}$. \\
\hline & $\begin{array}{l}\text { Bismuth } \\
\text { titanate (K12) }\end{array}$ & Max. temp: $820^{\circ} \mathrm{C}$, high Q factor (200). & Low coupling efficiency (12\%). \\
\hline & $\begin{array}{l}\text { Bismuth } \\
\text { titanate (K15) }\end{array}$ & Max. temp: $600^{\circ} \mathrm{C}$, good Q factor (100). & Only $10 \%$ bandwidth. \\
\hline & $\begin{array}{l}\text { Lead niobate } \\
(\mathrm{K}-81)\end{array}$ & Can achieve $60 \%$ bandwidth, $40 \%$ coupling efficiency. & $\begin{array}{l}\text { Max. temp. } 400^{\circ} \mathrm{C} \text {, low } \mathrm{Q} \text { factor } \\
\text { (15). }\end{array}$ \\
\hline & Lithium niobate & Operates to $1000^{\circ} \mathrm{C}$ & Low coupling efficiency (15\%). \\
\hline & Quartz & Max. Temp. $550^{\circ} \mathrm{C}$, very high Q factor (10000). & Low coupling efficiency (11\%). \\
\hline \multirow{5}{*}{ Transducer housing } & Stainless steel & $\begin{array}{l}\text { Common, inexpensive material. May wet in moving sodium for uniform heat } \\
\text { transfer. }\end{array}$ & \\
\hline & Nickel & Will likely wet in sodium. & \\
\hline & Titanium & Excellent strength-to-weight ratio. & $\begin{array}{l}\text { Expensive. Probably will not } \\
\text { wet with sodium. }\end{array}$ \\
\hline & $\begin{array}{l}\text { Alloy } 52 \\
\text { (nickel-iron) }\end{array}$ & Probably will wet in sodium. & \\
\hline & Invar & & $\begin{array}{l}\text { Probably will not wet with } \\
\text { sodium. }\end{array}$ \\
\hline
\end{tabular}


This current study suggests that the preferred transducer material for use in low-temperature sodium $\left(<250^{\circ} \mathrm{C}\right)$ is lead zirconate titanate or PZT (especially PZT-5A). The relatively low Curie temperature $\left(\mathrm{T}_{\mathrm{c}}\right)$ of this material $\left(365^{\circ} \mathrm{C}\right)$ precludes its use in sodium-cooled reactors at operating conditions $\left(550^{\circ} \mathrm{C}\right)$. Its high dielectric constant $\left(\varepsilon_{33} / \varepsilon_{0}=1800\right)$ and high charge and strain constants $\left(\mathrm{d}_{33}=390 \times\right.$ $10^{-12} \mathrm{C} / \mathrm{N}$ and $\mathrm{g}_{33}=24 \times 10^{-3} \mathrm{~V}-\mathrm{m} / \mathrm{N}$ ) make it an easy choice over high $\mathrm{T}_{\mathrm{c}}$ crystals such as lithium niobate. In addition, PZT has been shown to demonstrate excellent damage resistance both to neutrons (Moore et al. 1991) and gamma radiation (Severson 2004). Recently Kazys (2007) has reported on the development of high-temperature, radiation-resistant transducers of bismuth titanate for use in the leadbismuth cooled MYRRHA accelerator-driven non-critical fission core reactor. The ultrasonic transducers pursued for metal cooled fast reactor applications are of either the sintered ceramic type (e.g., lead zirconate titanate or "PZT") or single crystal (e.g., lithium niobate) (Cheeke 2002; Mix 2005) operating in compression/piston mode. Electromagnetic transducers used for traditional ultrasonic inspection in steels (such as electro-magnetic acoustic transducers) have not been used in molten sodium either for imaging, ranging, or acoustic emission (e.g., for monitoring sodium boiling or water ingress into the liquid sodium heat exchanger). The high-temperature limit of a piezoelectric transducer is principally determined by its Curie temperature, $\mathrm{T}_{\mathrm{C}}$, at which the transducer spontaneously depolarizes. Equally important, however, are the transducer thermal properties (heat conductivity and specific heat) because these may determine its sensitivity to thermal shock, a fracture mechanism when submerging an ultrasonic transducer in molten sodium. Severe thermal shock will fracture most piezoelectric materials rendering them unusable or severely degraded. This is an important consideration in designing the transducer electrodes so that, even though the transducer is cracked or fractured, electrical contact is maintained across both its front and rear surfaces.

\section{Backing material and bonding layer}

The bonding layer is a thin layer (a high-temperature Ag/Pb solder or epoxy) that bonds the transducer element to its backing layer. The backing material is usually an acoustically lossy ceramic (or rubber/elastomer) of the same acoustic impedance as the transducer material. The backing layer serves to minimize acoustic energy reflected from the back of the transducer.

\section{Compressible contact}

The rear electrode must maintain electrical contact with the entire back face of the transducer assembly (transducer element + backing layer), even if the unit is fractured due to thermal shock. For this reason Day and Smith (1974a) have used a woven disk of gold-coated wire, copper-beryllium mesh, or stainless steel foam to maintain electrical contact. This flexible electrode material is springloaded against the back side of the transducer assembly and is compliant with the backing layer topography, thus bridging small lateral fractures in the transducer-backing surface. If instead, electrical contact is made only at a single point on the transducer assembly rear face, fractures will severely diminish both the mechanical excitation and received ultrasonic signals.

\section{Assembly enclosure}

This review of historic and current activities in the development of ultrasonic-viewing systems suggests that the best material choice for the transducer enclosure is stainless steel, the same type used in the fast breeder reactor core. The literature suggests that even stainless steel will wet with liquid sodium after several hours of exposure. As long as the transducer face wets quickly, imaging data will be obtainable immediately after immersion. 


\section{Signal cable}

There are three primary considerations for ultrasonic (1-5 MHz) cables in a high-temperature, highradiation environment. First, the cable capacitance ( $\mathrm{pF} / \mathrm{foot}$ ) should be as low as possible to minimize attenuation of the transducer output. Second, to minimize signal reflections at the proximal and distal ends of the cable, the cable impedance should be matched to the impedance of the transceiver input/output and the transducer itself. Because cables are generally available with $50 \Omega$ characteristic impedances, matching at the transceiver end is typically not a problem. However, because piezoelectric transducers present a high resistance $(\mathrm{M} \Omega)$, capacitive $(\mathrm{nF})$ load, impedance matching at the transducer end will require additional, passive electrical components.

Two types of excitation/signal cable appear to be adequate for under-sodium viewing in a highradiation environment. Both of these cable types are also widely used in nuclear reactor facilities worldwide. The first is two-conductor "mineral cable."(a) Solid conductor rods of nickel or copper are inserted into a vertical sheath tube and kept at the correct (side-by-side) spacing with mineralinsulated block inserts. The tube is packed with magnesium oxide, which acts as a seal and fireproof insulator. The end of the sheath tube is sealed off and drawn down to the desired diameter.

Connectors are soldered or welded to each end. Because the magnesium oxide is hygroscopic, the cable must maintain its hermetic seal to maintain electrical integrity. This requires the use of special electrical connectors and factory termination.

Coaxial cable is also available for the high-temperature, high-radiation environment of the sodiumcooled. ${ }^{\text {(b) }}$ This cable uses $\mathrm{SiO}_{2}$ as the annular dielectric and can be obtained with $50 \Omega$ impedance in various diameters. Larger diameters are less flexible while smaller diameters exhibit higher insertion loss. Once again, this cable must be hermetically sealed to maintain electrical integrity, which requires factory termination.

\section{Electronics}

\section{a. Transducer excitation}

b. In the 1-5 MHz frequency range, transducer excitation is straightforward and may be achieved with commercial equipment (Swaminathan et al. 1990; Lennox et al. 1993; Karasawa et al. 2000). The transducer behaves as an undamped mechanical resonator. Maximum excitation pulse duration and repetition rate are determined by the range of the nearest target (the transducer oscillation must cease prior to the earliest returned pulse). A representative pulser design (Ord and Smith 1972a) appears in Figure 6.2.

If the piezoelectric transducer is driven over a length of coaxial cable, an impedance matching network should be used (at the transducer end) to minimize standing waves and/or pulse reflections back to the drive amplifier. This can be achieved using passive components (typically a $50 \Omega$ resistor across the transducer terminals or a matching transformer (Cheung and Levien 1985; Horowitz and Hill 1989).

(a) M.I. Cable Company, 1225 Price Plaza Drive, Katy, Texas, www.micable.com

(b) Meggitt Safety Systems, Simi Valley, California, www.stablecable.com 


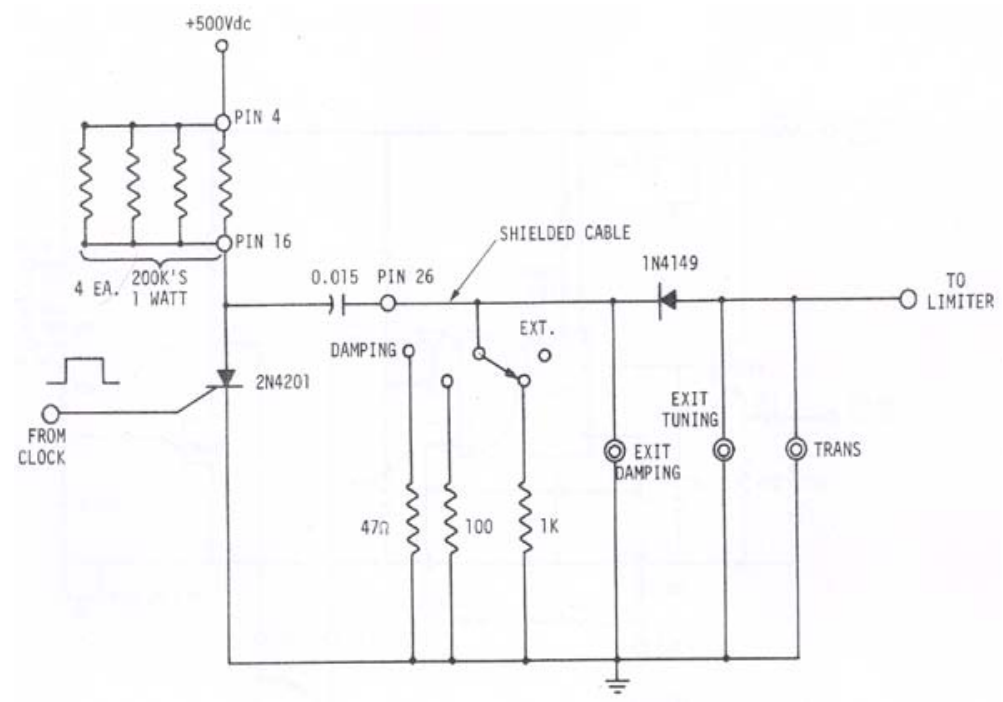

Figure 6.2. Excitation Circuit for Piezoelectric Transducer (Ord and Smith 1972a)

\section{c. Signal detection and processing}

Analog amplification of the radio frequency ultrasonic signal is straightforward (Da Silva et al. 2005; Pro-Wave 2005). However, to permit real-time or post-acquisition signal processing, highspeed digitization of the received waveform is advisable. Digitization permits signal averaging, feature extraction, frequency analysis, and implementation of signal-correlation techniques to better reject noise. Karasawa et al. (2000) achieved signal-to-noise improvement of $20 \mathrm{~dB}$ by cross-correlating the detected ultrasound signal with a pure sine wave at the resonant frequency of the transducer $(5 \mathrm{MHz})$.

\subsection{Mechanical and Synthetic Scanning to Obtain Ultrasonic Images}

To date, most of the demonstrated under-sodium viewing systems incorporate a single transducer with two scanning degrees of freedom (planar Cartesian coordinates in the X-Y plane or cylindrical coordinates, $\theta-\mathrm{Z}$ ). Three-dimensional imaging is possible using the ultrasonic pulse time-of-flight to and from the target. Past imager designs have been constrained by the fact that the reactor plant was designed and built prior to the decision to deploy an ultrasonic imager. Hence, the imager geometry and footprint are limited by the size of the vessel head access port and the available space between the reactor core and containment vessel walls. In the past, this has dictated use of small, single-transducer designs or linear scanners that must be carefully unfolded and manipulated into the observation space. If the imager can be designed in conjunction with the SFR vessel new options are possible. Of particular interest is the use of two-dimensional arrays to implement the synthetic aperture focusing technique (SAFT) or ultrasonic holography. The SAFT method can be used both for beam steering (Turnbull and Foster 1991; Huang et al. 2004; Jeyaraman et al. 2006) and for focusing ultrasonic reflections arising from a specific spatial point on a target (Acevedo et al. 2000; Wang et al. 2008).

SAFT is implemented by inserting time-varying electrical phase shifts (or delays) specific to each element in the transducer array. In this manner, the entire surface of a reflective target can be mapped without moving the array, an important consideration for spatially tight reactor vessels. Collins (1971) 
has suggested the use of ultrasonic holography for under-sodium imaging. Implementation of real-time holographic imaging methods requires the use of a two-dimensional ultrasonic transducer array.

In recent years, both SAFT and phased-array systems have been extensively deployed in medical applications. Systems are also receiving some use for the inspection of nuclear power plant components (Schuster et al. 2004).

\subsection{Radiation Damage in Piezoelectric Transducers}

There has been a long history of investigating radiation damage in piezoelectric materials, both for imaging systems and for acoustic emission (AE) applications (Decreton et al. 1997; Zachariasz et al. 2006; Lai et al. 2007). In general, radiation-hardened transducers tend to have a lower sensitivity $\left(\mathrm{d}_{33}\right)$, but there have been improvements in materials in recent years.

A summary review of gamma and neutron radiation damage in piezoelectric materials is given by Holbert et al. (2004; 2005). In general, inorganic piezoelectric materials (both crystalline and sintered ceramics) show minimal permanent damage due to gamma irradiation. The magnitude of gamma radiation effects on piezoelectric materials are material dependent. PZT is known to be quite radiation resistant (Lee et al. 1992). Radiation effects are most easily observed in the hysteresis curve (i.e., the D-E curve) for ferroelectric (piezoelectric) materials. Scott et al. (1989) observed that PZT films showed more symmetric hysteresis curves after $5 \mathrm{Mrad}(\mathrm{Si})$ regardless of their conditions during irradiation. Schwank et al. (1990) observed different D-E curve distortions when different bias conditions were applied during irradiation. Benedetto et al. (1990) observed that radiation-induced D-E curve distortion could be prevented by electrical cycling during irradiation and could be removed by post-irradiation electrical cycling. Lithium niobate shows no substantial changes in its piezoelectric properties even after exposure of $4 \times 10^{9} \mathrm{R}$ of ${ }^{60} \mathrm{Co}$ irradiation at high temperatures (Halverson et al. 1970).

Because neutron damage in materials is due to elastic collisions and displacement of atoms in the material matrix, cumulative dose effects are anticipated. However, PZT shows no significant degradation due to neutron exposure for fluencies at or below $10^{15} \mathrm{n} / \mathrm{cm}^{2}$ (Moore et al. 1991). Experimental data have not been found for neutron irradiation damage in lithium niobate. However because $\mathrm{LiNbO}_{3}$ exhibits a much higher $\mathrm{T}_{\mathrm{c}}\left(>1000^{\circ} \mathrm{C}\right)$ than PZT $\left(<400^{\circ} \mathrm{C}\right)$, it would be the preferred transducer material for inservice monitoring in a SFR vessel where operating temperatures $\sim 500^{\circ} \mathrm{C}$ are encountered (Smith 1970; Holbert et al. 2003; Holbert et al. 2004; Holbert et al. 2005).

\subsubsection{Alternative to Piezoelectric Transducers}

An alternative to the use of piezoelectric transducers for under-sodium viewing has been proposed by Takeishi et al. (1997). Differences between piezoelectric and optical ultrasonic probes are summarized in Figure 6.3. In the optical excitation scheme, the outgoing ultrasonic pulse is generated by incidence of a pulsed laser beam on the transducer diaphragm. Following excitation, diaphragm deflection due to returned ultrasonic energy is sensed with a fiber optic Fabry-Perot interferometer. A schematic of the optical-ultrasonic imaging system appears in Figure 6.4. The authors suggest the advantages of the optical method over the traditional piezoelectric transducer approach include: (1) more uniform generation of the outgoing ultrasonic excitation pulse (less transducer-to-transducer variability than a 
piezoelectric array); (2) the ability to miniaturize the transducer array; and (3) use of optical fiber offers improved immunity against electrical noise.

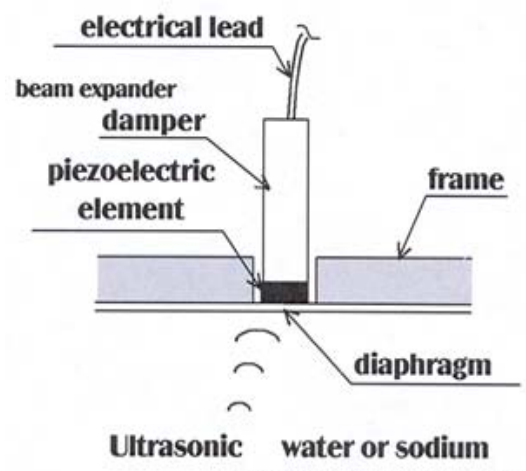

(a)piezoelectric element

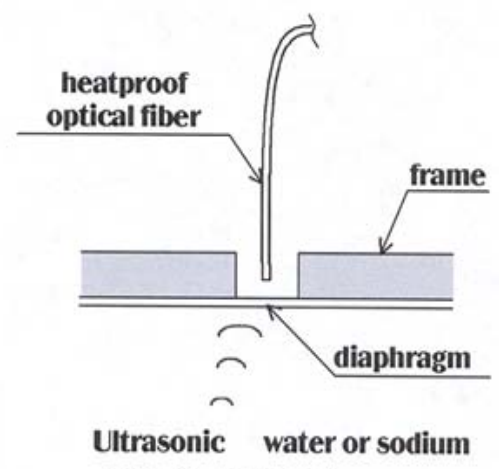

(b)optical element

Figure 6.3. Structural Difference between Piezoelectric and Optical Ultrasonic Transducers (Takeishi et al. 1997)

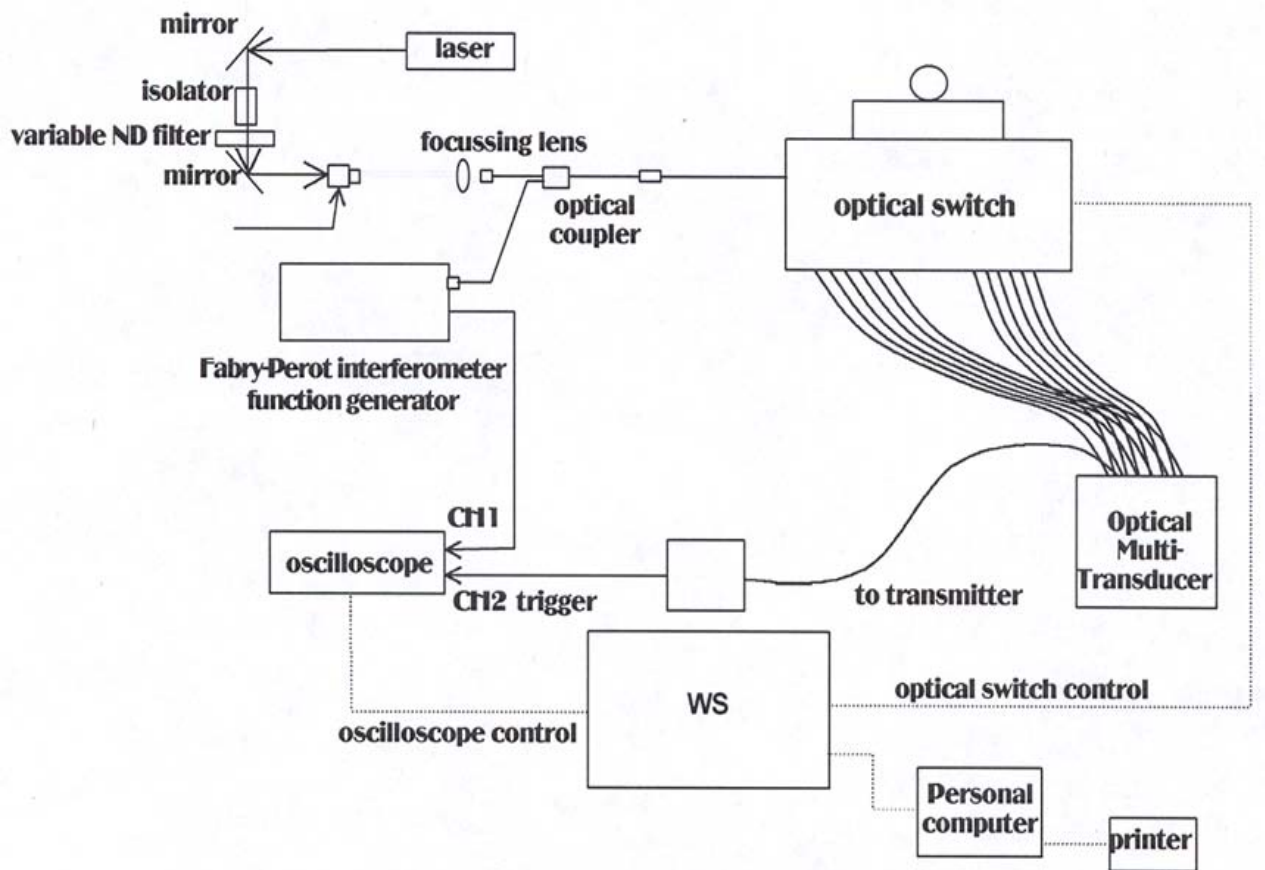

Figure 6.4. Experimental Setup to Implement Optical Transducer Array (Takeishi et al. 1997) 



\subsection{High-Temperature Acoustic Waveguides}

Use of waveguides to deliver and receive sound waves in a hostile environment has been in practice for years. An acoustic waveguide is a mechanical structure along which an elastic wave can propagate from a sensing location in the medium being monitored to a receiving transducer that converts the elastic energy to an electrical signal. The basic design of an acoustic waveguide consists of a piezoelectric transducer bonded on a wave-guiding structure such as a metal rod. The waveguide acts as a buffer rod that isolates the sensing transducer from a high-temperature and corrosive medium. Because the transducer is kept in a relatively cool environment, below the Curie temperature of its piezoelectric element, the transducer can perform with better reliability. Furthermore, the waveguide design is more suitable for applications that have space constraints because the size and shape of a waveguide can be modified to conform to the available space. The motivation for developing a high-temperature acoustic waveguide for the under-sodium viewing system is to reduce the cost and complexity of the transducer design and to enhance the transducer performance, reliability, and detection sensitivity achievable using piezoelectric materials with high coupling coefficients such as PZT ceramics.

The waveguide transducer design can withstand high pressure and corrosion attack, but measurements become more complicated due to multiple reflections inside the waveguide. When operating in pulseecho mode, spurious echoes due to dispersion, wave reverberation, mode conversion, and diffraction within the waveguide cause poor signal-to-noise ratio $(\mathrm{S} / \mathrm{N})$ and thus reduce the detection sensitivity. Different waveguide designs have been proposed and reported in an effort to achieve S/N improvement. In a recent paper by Lynnworth (2005), past and recent waveguide developments were summarized. The common waveguide design problems were identified in another recent transducer review paper (Kazys et al. 2008). The problems that need to be addressed include the acoustic coupling between the ultrasonic transducer and the waveguide, transmission of ultrasound through the waveguide, and the selection of waveguide material. In the case that a dispersionless propagation of the ultrasonic wave inside the waveguide is required, the diameter or thickness $d$ of the waveguide is restricted by the relation (Eckert et al. 2003) of $d f / c<0.1$, where $f$ and $c$ are sound frequency and velocity, respectively. The diameter of the waveguide also determines the beam divergence in the liquid, which in turn affects the resolution. The half angle of the beam divergence can be estimated from $\theta=\arcsin (1.22 \lambda / d)$ where $\lambda$ is the wavelength in the waveguide.

Reported waveguide designs that are relevant to the under-sodium viewing applications are briefly described below.

\subsection{Smooth Rod}

The simplest waveguide design is a cylindrical solid rod. Anderson (1972) presented a theoretical and experimental analysis for designing such an acoustic waveguide for service in LMFBRs. The waveguide is a stainless steel cylindrical rod to which an electromechanical transducer is mounted at one end of the rod. Figure 7.1 shows the waveguide that was tested in a high-temperature, low-pressure sodium loop. 


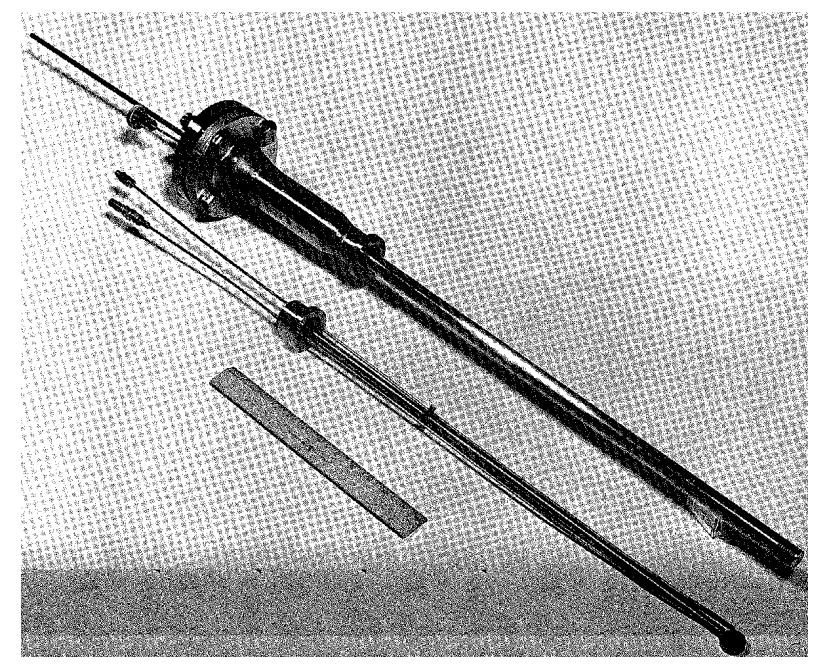

Figure 7.1. Smooth Rod Acoustic Waveguide Tested in the LMFBR Simulation Heat Transfer Loop (Anderson 1972)

Recently, waveguides of cylindrical rod geometry were evaluated (Hatano 2005) for transmitting and radiating high-power ultrasound at high frequencies. A cylindrical rod with a diameter several times larger than the wavelength can be used as an efficient waveguide. Standing waves in the axial direction can be established when the length of the rod is set to a multiple of half wavelength.

\subsection{Threaded Rod}

If a smooth rod conveys longitudinal waves, sidewall reflections cause mode conversion to shear waves, resulting in energy loss and generation of spurious delayed echoes. Threading (Lynnworth 1989) is the commonly used technique for reducing the sidewall reflections. Typically, the buffer rod is made of solid metal (sometimes steel and occasionally tungsten) $15-25 \mathrm{~mm}$ in diameter for $2-10 \mathrm{MHz}$ ultrasonic frequency. The external surface is threaded or grooved to break up unwanted mode conversions. The threaded waveguides worked well at high frequencies $(2-10 \mathrm{MHz})$ where the rod radius was $>3 \lambda$ ( $\lambda$ is the wavelength, $\lambda=1.13 \mathrm{~mm}$ at $5 \mathrm{MHz}$ ). However, application of threaded waveguides in sodium-cooled reactors has not been reported.

\subsection{Focused Clad Rod}

Use of clad rods as high-temperature ultrasonic waveguides is a relatively new approach. They have been successfully applied to ultrasonic imaging under molten metals (Ihara et al. 2000; Rehman et al. 2001; Ono et al. 2002b; Ono et al. 2003, 2004; Ono et al. 2006). The clad buffer rod consists of a mild steel core with a double-tapered shape, a thermal sprayed stainless steel inner cladding, and bronze outer cladding. The porous structure of the cladding layer is produced by thermal spray results in high ultrasonic loss and low ultrasonic impedance. The outer bronze cladding is merely used to improve the cooling efficiency at the air-cooling channel. Figure 7.2 shows the design of the clad buffer rod. The clad buffer rod gives better $\mathrm{S} / \mathrm{N}$ than a non-clad rod by reducing the leakage of ultrasonic energy from the periphery of the rod into surrounding molten metal. In addition, a non-clad buffer rod supports many higher-order propagation modes; whereas, a clad buffer rod supports much fewer lower-order propagation 
modes. For better spatial resolution, a spherical concave surface was machined at the end of the clad, tapered buffer rod. The lens has a radius, $\mathrm{R}$, of $4.75 \mathrm{~mm}$ and an aperture diameter, $\mathrm{D}$, of $7.0 \mathrm{~mm}$. The lateral resolution $\mathrm{dr}=\mathrm{Kr} \lambda \mathrm{F} / \mathrm{D}$ and the focusing depth $\mathrm{dz}=4 \mathrm{Kz} \lambda(\mathrm{F} / \mathrm{D})^{2}$, where $\mathrm{F}$ is the focal length and can be estimated from $\mathrm{R} /\left(1-\mathrm{V}_{2} / \mathrm{V}_{1}\right)\left(\mathrm{V}_{1}\right.$ and $\mathrm{V}_{2}$ are the longitudinal velocities in the steel buffer rod and in liquid metal, respectively).

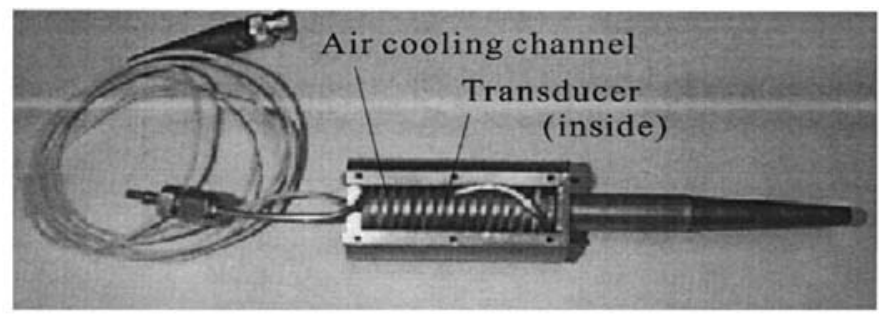

(a)

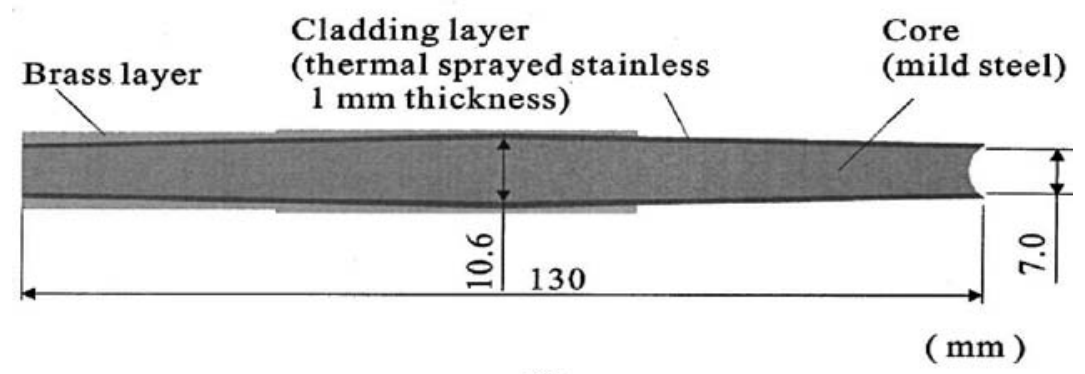

(b)

Figure 7.2. Clad Buffer Rod with a Double-Taper Shape: (a) external view with cooling channel, (b) schematic diagram (Ihara et al. 2000)

\subsection{Bundle Waveguide}

A bundle waveguide transducer (Lynnworth et al. 2005) is constructed with a bundle of acoustically slender metal rods, each thin compared to wavelength, tightly packed within a sheath and welded closed at each end. It provides a dispersion-free waveguide assembly that acts as a thermal buffer between the piezoelectric transducer and the hot fluid medium. It is reported that the waveguide assembly can withstand temperatures up to $450^{\circ} \mathrm{C}$. Figure 7.3 shows the basic design of the waveguide and the industrial version that is supplied by GE Panametrics. 


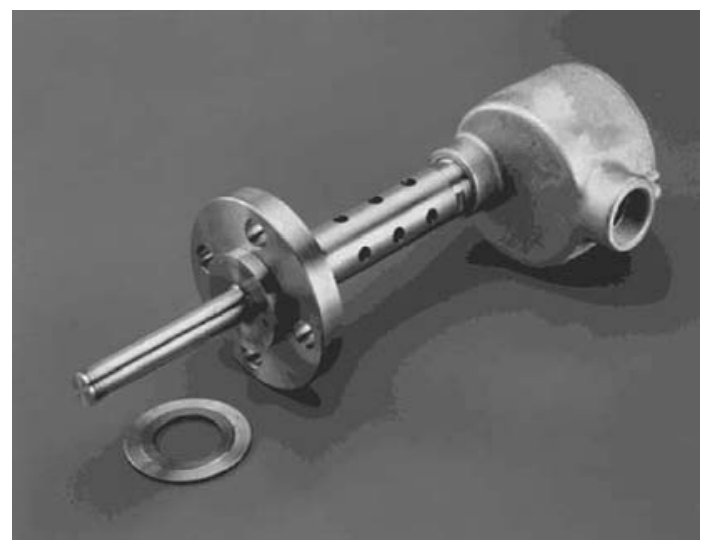

(a)

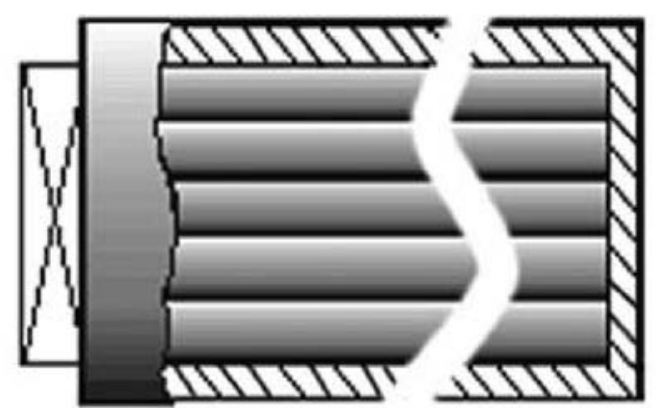

(b)

Figure 7.3. Extensional Bundle Waveguide: (a) typical industrial version and (b) basic bundle design (Boehmer et al. 1975)

\subsection{Spiraled Sheet Waveguide}

The spiraled sheet waveguide (SPW) is a recently patented technology (Heijnsdijk and van Klooster 2002). The waveguide consists of a coiled foil, metal or ceramic, whose layer thickness is considerably less than the wavelength of the ultrasonic signal. The result is that ultrasonic signal interference and attenuation in the waveguide due to scattering and dispersion are largely avoided. An ultrasonic transducer is typically mounted at one end of the coiled foil. This waveguide end is generally welded together with a smooth surface for ultrasonic transmission. Figure 7.4 shows such a waveguide developed for application of ultrasonic Doppler velocimetry in liquid metals at high temperatures above $200^{\circ} \mathrm{C}$ (Eckert et al. 2003). The waveguide was made from a stainless steel foil with a thickness of $0.1 \mathrm{~mm}$ that was wrapped axially around a capillary tube. The waveguide was closed at the front end by means of laser beam melting resulting in a flat stainless steel surface.

As an indication of the diversity of high-temperature ultrasonic waveguide development performed at ANL, Figure 7.5 illustrates four additional designs. 

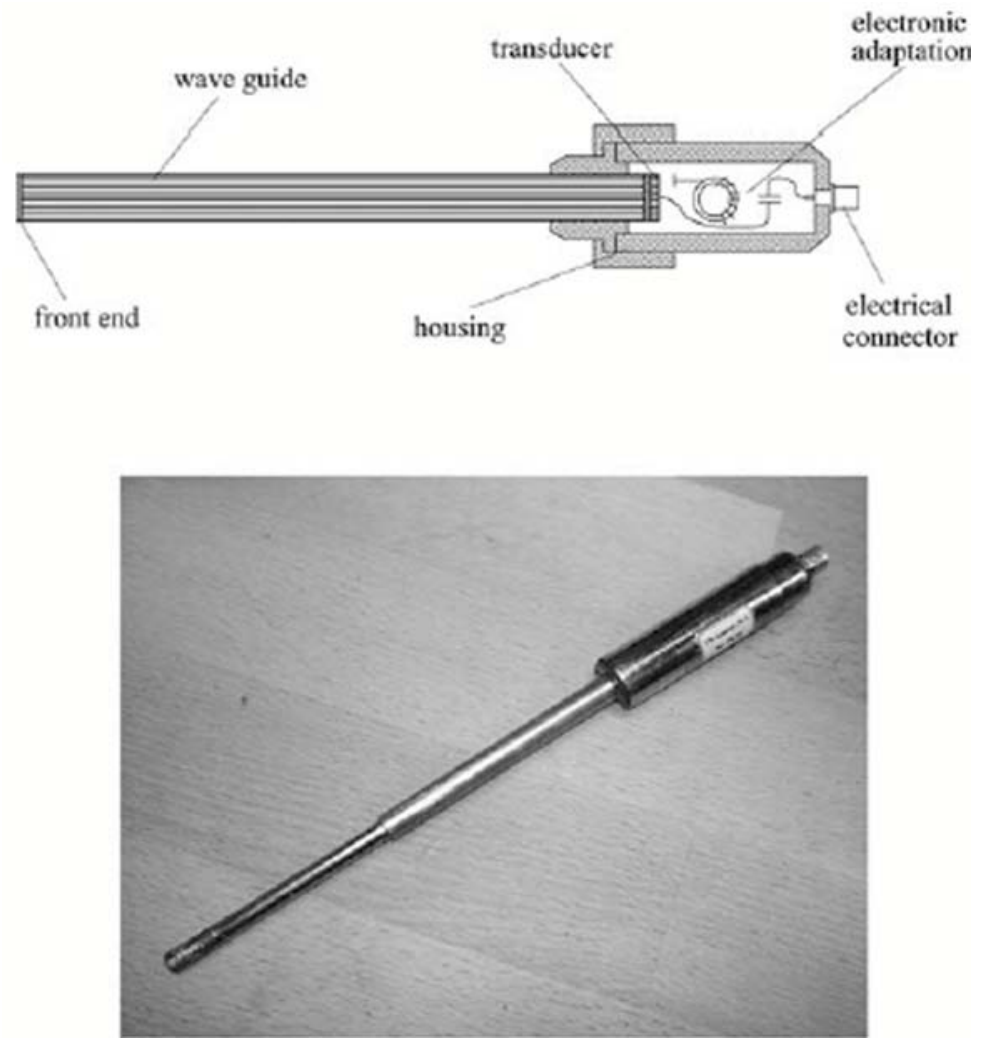

Figure 7.4. Schematic View and Photograph of the Spiraled Sheet Ultrasonic Waveguide (Boehmer and Smith 1976) 

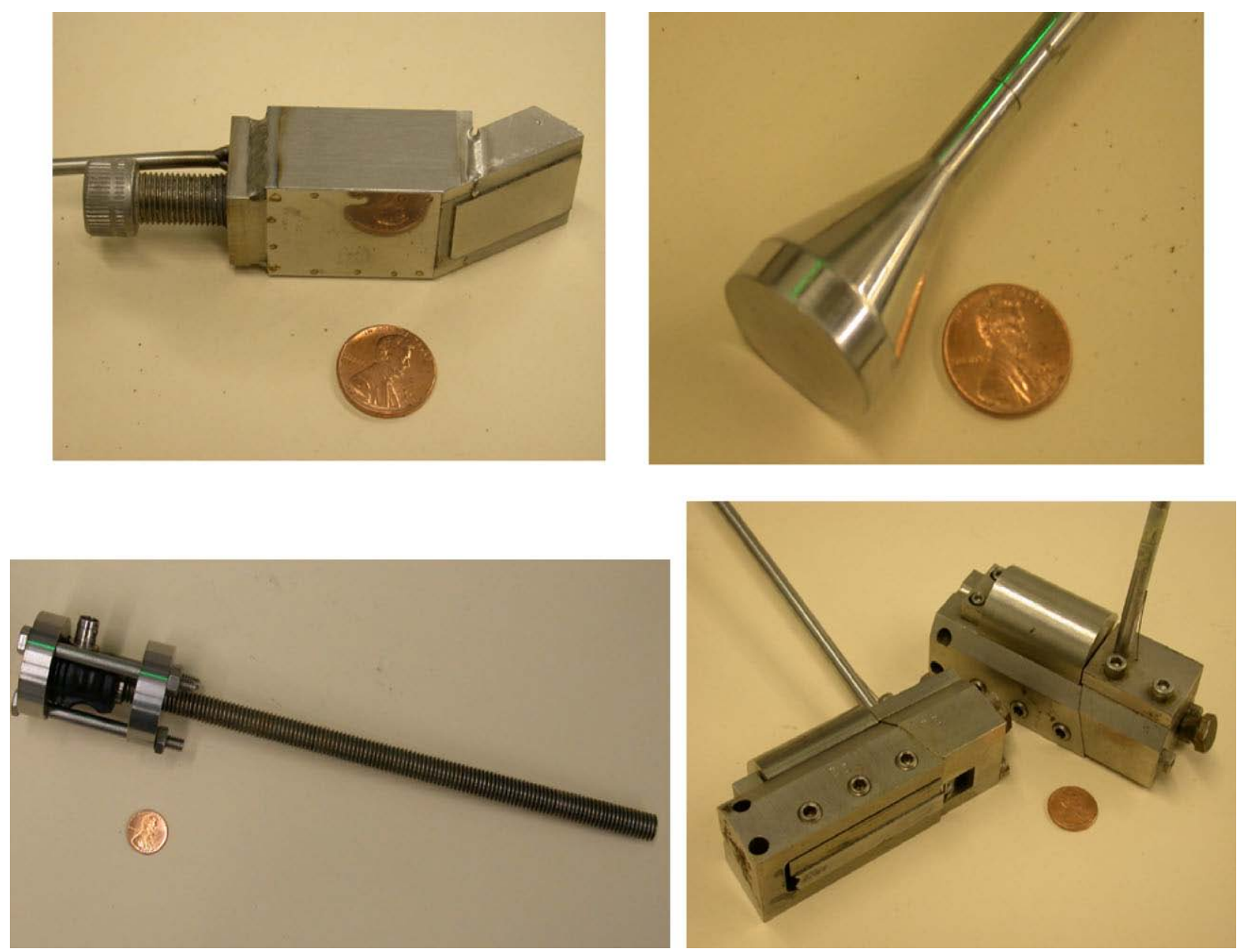

Figure 7.5. Additional High-Temperature Ultrasonic Waveguide Systems Developed at ANL 


\subsection{Conclusions and Unresolved Issues}

This review has focused on an assessment of the current and past state of the art, and it has considered insights to be gained from piezoelectric transducers used in fast reactor applications for (i) imaging, (ii) inspection - monitoring (NDT), and (iii) other instrumentation. This review has served to identify several "best options" regarding design and demonstration of a scanned, single-transducer under-sodium viewing system.

These options are summarized below.

\subsection{Piezoelectric Materials}

From the standpoint of high temperature operation $\left(\mathrm{T} \leq 250^{\circ} \mathrm{C}\right)$, the preferred transducer materials are PZT, lithium niobate, or lead metaniobate. Transducer thickness should be $\lambda / 2$ in the material at the operating frequency. An operating frequency of approximately $5 \mathrm{MHz}$ appears to be optimum. The transducer surface must be isolated from molten sodium with a thin flexible diaphragm (e.g., of stainless steel) bonded to the piezoelectric material. Matching of transducer-diaphragm thermal expansion coefficients is very important to prevent thermal shock damage. The bonding material used (e.g., silver solder) should have sufficient ductility to minimize stresses at the transducer-diaphragm interface.

\subsection{Integrated Transducer (front face)}

Rapid, thorough sodium wetting of the ultrasonic transducer diaphragm surface is imperative. This can be achieved with a thin (sacrificial) gold coating, use of polished nickel, or possibly with polished stainless steel (if the sodium flow impinges on the diaphragm surface). Submerged transducer testing must be performed at design temperature $\left(250^{\circ} \mathrm{C}\right)$ in liquid sodium to verify wetting and transceiver performance.

\subsection{Transducer Electrodes}

In the event of piezoelectric transducer fracture due to thermal transients (which may be unavoidable), electrical contact must be maintained with all the fragments. This can be achieved using a wire mesh to contact the back electrode. The wire mesh will conform to transducer surface irregularities and permit collection of all generated electrical charges.

\subsection{Transducer Housing}

Stainless steel appears to tolerate the high-temperature, molten sodium environment over extended periods. Only the front transducer face (driven by the piezoelectric transducer) needs to be modified to achieve sodium wetting. 


\subsection{Ultrasonic Waveguides}

Ultrasonic waveguide designs should be thoroughly evaluated as a solution to transducer thermal shock damage. Sodium wetting of the distal waveguide end (i.e., the end in the liquid sodium) must be verified at operating temperature $\left(250^{\circ} \mathrm{C}\right)$. Waveguide attenuation and propagation mode effects must be quantified in both the transmit- and receive-directions.

\subsection{Signal Cables}

Short, low-capacitance, coaxial, high-temperature, radiation-resistant cables are required. This type of cable is available commercially with a $\mathrm{SiO}_{2}$ dielectric. Piezoelectric transducer impedance should be matched with a passive matching network to cable impedance to minimize spurious signals.

\subsection{Signal Processing}

Received ultrasonic signals should be digitized at ten times the maximum anticipated frequency (50 MHz digitization rate for a 5-MHz transducer). This will permit signal post-processing (e.g., crosscorrelation) to improve signal/noise ratio.

\subsection{Modeling}

To support the USV imager design process, simple predictive models should be developed to enable rapid evaluation of design options (e.g., transducer diameter/thickness, piezoelectric material, temperature effects, electrical impedance properties, etc.) and their impact on image quality. Such models would especially facilitate an assessment of linear and two-dimensional array designs that could use synthetic aperture focusing techniques. 


\subsection{References}

Acevedo P, J Juarez and S Rodriguez. 2000. "Development of an Ultrasonic Focusing System Based on the Synthetic Aperture Focusing Technique.” In Acoustical Imaging, Volume 24. ed: KH Lee. Kluwer Academic/Plenum Publishers, New York. pp. 27-34.

Anderson TT. 1972. Tentative Design Analysis Guide for Acoustic Waveguides. ANL-ETD-72-05. Argonne National Laboratory, Argonne, Illinois.

Ando M, S Kubo, Y Kamishima and T Iitsuka. 2006. "Study on In-Service Inspection Program and Inspection Technologies for Commercialized Sodium-Cooled Fast Reactor.” Proceedings of ICONE14 International Conference on Nuclear Engineering. Miami, Florida. ASME. Paper \#89558.

Baque F. 2005. "Review of In-Service Inspection and Repair Technique Developments for French Liquid Metal Fast Reactors.” Nucl. Tech. 150(1):67-78.

Barrett LM, JA McKnight and JR Forthergill. 1984. “Ultrasonic Viewing in Fast Reactors.” Phys. Tech. 15(6):308-314.

Becker FL and RL Trantow. 1971. Ultrasonic Isometric Imaging. HEDL-SA-287. Westinghouse Hanford Co., Richland, Washington.

Benedetto JM, RA Moore, FB McLean, PS Brody and SK Dey. 1990. “The Effect of Ionizing Radiation on Sol-Gel Ferroelectric PZT Capacitors.” IEEE. Trans. Nucl. Sci. 37(6):1713-1717.

Boehmer LS and RW Smith. 1976. "An Ultrasonic Instrument for Continuous Measurement of Sodium Levels in Fast Breeder Reactors.” IEEE Trans. Nucl. Sci. 23(1):359-362.

Boehmer LS, RW Smith and CK Day. 1975. An Ultrasonic Instrument for Continuous Measurement of Sodium Level. HDCL TC-245. Hanford Engineering Development Laboratory, Richland, Washington.

Bond LJ. 1988. "Review of Existing NDT Technologies and Their Capabilities.” In Proc. of AGARD/SMP Review of Damage Tolerance for Engine Structures; 1. Non-Destructive Evaluation, pp. 21 through 2-16. May 1-6, 1988, Luxembourg. AGARD.

Bond LJ, SR Doctor, KJ Bunch, MS Good and AE Waltar. 2007a. "Instrumentation, Monitoring and NDE for New Fast Reactors.” Advanced Nuclear Fuel Cycles and Systems (GLOBAL 2007). September 9-13, 2007. Boise, Idaho. American Nuclear Society, La Grange Park, Illinois. pp. 1274-1279.

Bond LJ, SR Doctor, KJ Bunch, MS Good and AE Waltar. 2007b. "Instrumentation, Monitoring and NDE for New Fast Reactors.” In Global 2007, Advanced Nuclear Fuel Cycles and Systems, pp. 12741279. September 9-13, 2007, Boise, Idaho. American Nuclear Society.

Bond LJ and N Saffari. 1984. “Mode Conversion Ultrasonic Testing.” In Research Techniques in NonDestructive Testing, Vol. 7. ed: RS Sharpe. Ch. 5. Academic Press, London. pp. 145-189. 
Broomfield GH. 1980. “The Effect of Low-Fluence Neutron Irradiation on Silver-Electroded LeadZirconate-Titanate Piezoelectric Ceramics.” J. Nucl. Mater. 91(1):23-34.

Broomfield GH. 1985. The Effect of Temperature and Irradiation on Piezoelectric Acoustic Transducers and Materials. UKAEA Report AERE-R 11 942. United Kingdom Atomic Energy Authority Harwell, United Kingdom.

Cheeke JDN. 2002. Fundamentals and Applications of Ultrasonic Waves. CRC Press, Boca Raton. ISBN 0849301300.

Cheung SW and FH Levien, Eds. 1985. Microwaves Made Simple: Principles and Applications. Artech House, Inc., Chelsea, Michigan.

Collins HD. 1971. Various Holographic Scanning Configurations for Under-Sodium Viewing. BNWL1558. Battelle Northwest, Richland, Washington.

Cross BT. 1967. Ultrasonic Inspection of Weldments Using the Delta Technique. Automation Industries, Research Division, Boulder, Colorado. NTIS Accession Number AD0196546.

Da Silva JJ, MG Wanzeller, P De Almeida Farias and JS Da Rocha Neto. 2005. "Development of circuits for excitation and reception in ultrasonic transducers for generation of guided waves in hollow cylinders for fouling detection.” In Proceedings of the IEEE Instrumentation and Measurement Technology Conference, Vol. 1, pp. 467-471. May 17-19, 2005, Ottawa, Canada. Institute of Electrical and Electronics Engineers Inc.

Day CK and RW Smith. 1974a. "Under-Sodium Viewing.” IEEE Ultrasonics Symposium. November 1974. Monterey, California. IEEE. p. 21. Paper \#CONF-731128-1. HEDL-SA-615, Hanford Engineering Development Lab, Richland, Washington.

Day CK and RW Smith. 1974b. “Under Sodium Viewing.” IEEE Trans. Ultra. US-21(3).

Decreton M, S Coenen and JD Geeter. 1997. "Implementing Radiation Hardened Sensors for Computer Aided Teleoperation in a Nuclear Environment.” ISIE'97, IEEE International Symposium on Industrial Electronics. July 7-11, 1997. Guimaraes, Portugal. IEEE, Piscataway, New Jersey. pp. SS278-SS284.

Eckert S and G Gerbeth. 2002. "Velocity Measurements in Liquid Sodium by Means of Ultrasound Doppler Velocimetry.” Exp. Fluid. 32(5):542l-546.

Eckert S, G Gerbeth and VI Melnikov. 2003. "Velocity Measurements at High Temperatures by Ultrasound Doppler Velocimetry Using an Acoustic Wave Guide.” Exp. Fluid. 35(5):381-388.

Eggeman T. 2007. "Sodium and Sodium Alloys.” In Kirk-Othmer Enclopedia of Chemical Technology. John Wiley and Sons, Washington.

Foust OJ, Ed. 1972. Sodium-NaK Engineering Handbook, Vol. 1. Gordon and Breach, Science Publisheers, Inc., New York. 
Gavin AP and TT Anderson. 1971. "High-Temperature Acoustic Sensors for Boiling Detection.” IEEE. Trans. Nucl. Sci. 18(1):340-344.

Halverson SL, TT Anderson, AP Gavin and T Grate. 1970. "Radiation Exposure of a Lithium Niobate Crystal at High Temperatures.” IEEE. Trans. Nucl. Sci. 17(6):335-340.

Hannah KJ. 1968. Development of the Ultrasonic Delta Technique for Aluminum Welds and Materials. Automation Industries, Research Division, Boulder, Colorado. NTIS Accession Number AD0196245.

Hans R, E Kranz and H Weiss. 1984. "Under Sodium Viewing - A Method to Identify Objects in an Opaque Medium.” In Liquid Metal Engineering and Technology: Volume 1, Proceedings of the Third International Conference, pp. 419-421. April 9-13, 1984, London, England. British Nuclear Energy Society.

Hatano H. 2005. "Waveguide for Transmitting and Radiating High-Frequency, High-Power Ultrasound Using Higher Mode Vibrations of a Cylindrical Rod.” IEEE Trans. Ultrason. Ferroelectrics Freq. Contr. 52(4):518-524.

Hayes DJ. 1974. “Instrumentation for Liquid Sodium in Nuclear Reactors.” J. Phys. E Sci. Instrum. 7(2):69-75.

Heijnsdijk AM and JM van Klooster. 2002. “Ultrasonic Waveguide.” U.S. Patent 6,400,648.

Hess B and E Ruppert. 1975. "Instrumentation for Core and Coolant Monitoring in Liquid-Metal Fast Breeder Reactors.” Atom. Energ. Rev. 13(1):81-144.

Holbert K, S Sankaranarayanan and SS McCready. 2005. "Response of Lead Metaniobate Acoustic Emission Sensors to Gamma Radiation.” IEEE. Trans. Nucl. Sci. 52(6):2583-2590.

Holbert KE, S Sankaranarayanan, SS McCready, DR Spearing and AS Heger. 2003. "Response of Piezoelectric Acoustic Emission Sensors To Gamma Radiation.” RADECS 2003; Proceedings of the 7th European Conference on Radiation and Its Effects on Components and Systems, 2003. September 15-19, 2003. Noordwijk, The Netherlands. IEEE. pp. 559-565.

Holbert KE, S Sankaranarayanan, SS McCready, DR Spearing and AS Heger. 2004. "Response of Piezoelectric Acoustic Emission Sensors to Gamma Radiation.” In Proceedings of the 7th European Conference on Radiation and its Effects on Components and Systems, RADECS 2003, pp. 559-565. September 15-19, 2003, Noordwijk, 2200 AG, Netherlands. European Space Agency, (Special Publication) ESA SP.

Horowitz P and W Hill. 1989. The Art of Electronics, 2nd Edition. Cambridge University Press, Cambridge, United Kingdom.

Huang J, PW Que and JH Jin. 2004. “A Parametric Study of Beam Steering for Ultrasonic Linear Phased Array Transducer.” Russian Journal of Nondestructive Testing 40(4):254-259.

Ihara I, CK Jen and DR Franca. 2000. "Ultrasonic Imaging, Particle Detection, and V(z) Measurements in Molten Zinc Using Focused Clad Buffer Rods.” Rev. Sci. Instrum. 71(9):3579-3586. 
Imbert C, JL Berton and G Gimenez. 1996. "Realization of ultrasonic images of immersed metallic structures using a digital beamforming system. Experimental study.” In Proceedings of the IEEE Ultrasonics Symposium, Vol. 1, pp. 765-770. Piscataway, New Jersey. IEEE.

Jasiuniene E. 2007. "Ultrasonic Imaging Techniques for Non-Destructive Testing of Nuclear Reactors Cooled by Liquid Metals: Review.” Ultragarsas (Ultrasound) 62(3):30-43.

Jeyaraman S, B Ganesan and M Kumar. 2006. “Ultrasonic Beam Steeering in Isotopic Media.” Proceedings of the COMSOL Users Conference. November 17, 2006. Bangalore.

Joo Y-S and J-H Lee. 2005. "Beam Steering Technique of Ultrasonic Waveguide Sensor for UnderSodium Inspection of Sodium Fast Reactor.” 13th International Conference on Nuclear Engineering (ICONE-13/2005). Korea Atomic Energy Research Institute.

Karasawa K, M Izumi, T Suzuki, S Nagai, M Tamura and S Fujimori. 2000. "Development of Undersodium Three-dimensional Visual Inspection Technique Using Matrix-arrayed Ultrasonic Transducer.” $J$. Nucl. Sci. Tech. 37(9):769-779.

Kazys R, A Voleisis, R Sliteris, L Mazeika, R Van Nieuwenhove, P Kupschus and AA Hamid. 2005. "High Temperature Ultrasonic Transducers for Imaging and Measurements in a Liquid $\mathrm{Pb} / \mathrm{Bi}$ Eutectic Alloy.” IEEE Trans. Ultrason. Ferroelectrics Freq. Contr. 52(4):525-537.

Kazys R, A Voleisis, R Sliteris, B Voleisiene, L Mazeika and HA Abderrahim. 2007. "Research and Development of Radiation Resistant Ultrasonic Sensors for Quasi-Image Forming Systems in a Liquid Lead-Bismuth.” Ultragarsas (Ultrasound) 62(3):7-15.

Kazys R, A Voleisis, R Sliteris, B Voleisiene, L Mazeika, PH Kupschus and HA Abderrahim. 2006. "Development of Ultrasonic Sensors for Operation in a Heavy Liquid Metal.” IEEE Sensor J 6(5):11341143.

Kazys R, A Voleisis and B Voleisiene. 2008. "High Temperature Ultrasonic Transducers: Review.” Ultragarsas (Ultrasound) 63(2):7-17.

Lai C-C, C-Y Chang, Y-Y Wei and W-S Wang. 2007. "Study of Gamma-Irradiation Damage in LiNbO3 Waveguides.” IEEE Photon. Tech. Lett. 19(13):1002-1004.

Lee SC, G Teowee, RD Schrimpf, DP Birnie, III, DR Uhlmann and KF Galloway. 1992. "Total-Dose Radiation Effects on Sol-Gel Derived PZT Thin Films.” IEEE. Trans. Nucl. Sci. 39(6):2036-2043.

Lennox T, JA McKnight and R Rowley. 1993. “Application of Acoustic Instrumentation for Use in Liquid Metal Fast Breeder Reactors.” Nucl. Energ. 32(1):29-40.

Lynnworth LC. 1989. Ultrasonic Measurements for Process Control: Theory, Techniques, Applications. Academic Press, Inc., San Diego, California.

Lynnworth LC, Y Liu and JA Umina. 2005. "Extensional Bundle Waveguide Techniques for Measuring Flow of Hot Fluids.” IEEE Trans. Ultrason. Ferroelectrics Freq. Contr. 52(4):538-544. 
Mazeika L, E Jasiuniene, R Kazys, R Sliteris, R Raisutis, HA Abderrahim and M Dierckx. 2007. “3D Acoustic Model of a Nuclear Reactor Cooled by Liquid Metal Alloy for Investigation of Ultrasonic Imaging Systems.” 2007 ICU Vienna: International Congress on Ultrasonics. April 9-12, 2007. Vienna University of Technology.

McKnight JA. 1988. “The Use of Ultrasonics for Monitoring the Internal Structure of a LMFBR.” In Proc. Fourth International Conference on Liquid Metal Engineering and Technology (LIMET '88), pp. 106-1 to 106-10.Avignon, France. Societe Francaise d’Energie Atomique.

McKnight JA, EJ Burton and P Fenemore. 1984. "Recent Advances in the Technology of Under-Sodium Inspection in LMFBRs." In Liquid Metal Engineering and Technology: Volume 1, Proceedings of the Third International Conference, pp. 423-430. April 9-13, 1984, London, England. British Nuclear Energy Society.

Mech SJ and JD Martin. 1982. "Ultrasonic Inspection of Liquid-Metal-Filled Austenitic Stainless Steel Piping Welds.” International Conference on Quantitative NDE in the Nuclear Industry. May 10, 1982. San Diego, California.

Mix PE. 2005. Introduction to Nondestructive Testing: A Training Guide. 2nd Ed. Wiley, Hoboken, New Jersey. ISBN 0471420298.

Moore RA, JM Benedetto, JM McGarrity and FG McLean. 1991. "Neutron Irradiation Effects on PZT Thin Films for Nonvolatile-Memory Applications.” IEEE Trans. Nucl. Soc. 38(6):1078-1082.

Nakamoto K, K Ishii, N Ohyama, S Tamura and K Yamamoto. 1984. "Eddy Current Type Void Detector for LMFBR Core Monitoring.” Liquid Metal Engineering and Technology: Volume 1, Proceedings of the Third International Conference. April 9-13, 1984. Oxford, England. British Nuclear Energy Soc. pp. 431-432.

Ono Y, M Kobayashi, O Moisan and J Cheng-Kuei. 2006. "High-temperature and broadband immersion ultrasonic probes.” IEEE Sensor J 6(3):580-587.

Ono Y, J-F Moisan and C-K Jen. 2003. "Ultrasonic Techniques for Imaging and Measurements in Molten Aluminum.” IEEE Trans. Ultrason. Ferroelectrics Freq. Contr. 50(12):1711-1721.

Ono Y, J-F Moisan and C-K Jen. 2004. “Ultrasonic Imaging in Molten Magnesium.” Meas. Sci. Technol. 15:N25-N29.

Ono Y, JF Moisan, CK Jen and DR Franca. 2002a. "Development of Ultrasonic Techniques with Buffer Rod in Molten Aluminum.” In Proceedings of the IEEE Ultrasonics Symposium, Vol. 1, pp. 805-810. Institute of Electrical and Electronics Engineers Inc.

Ono Y, JF Moisan, CK Jen and DR Franca. 2002b. "Development of Ultrasonic Techniques with buffer Rod in Molten Aluminum.” Proceedings of the IEEE Ultrasonics Symposium. October 8-11, 2002. Munich, Germany. Institute of Electrical and Electronics Engineers. pp. 805-810. 
Ord RN and RW Smith. 1972a. Development of an Under-Sodium Ultrasonic Scanner for In-Reactor Surveillance. HEDL-TME-72-91. Hanford Engineering Development Laboratory, Richland, Washington.

Ord RN and RW Smith. 1972b. Ultrasonic Under-Sodium Viewing System Development for the FFTF. HEDL-SA-335. Westinghouse Hanford Co., Richland, Washington.

Pro-Wave. 2005. Selection and Use of Ultrasonic Ceramic Transducers. Application Note AP050830. Pro-Wave Electronics Corp., PO Box 1-70 Chung Ho, Taiwan, ROC. Phone 886-2-22465101. Available at http://www.prowave.com.tw.

Rajendran A, C Asokane, G Elumalai and K Swaminathan. 1996. "Development of an Ultrasonic UnderSodium Scanner for the Fast Breeder Test Reactor.” In NDT in Nuclear Industry, Proceedings of the 14th World Conf. on Non-destructive Testing, Vol. 2, pp. 349-352. December 8-13, 1996, New Delhi, India. Ashgate Publishing Company.

Rehman A-U, C-K Jen and I Ihara. 2001. "Ultrasonic Probes for High Temperature Immersion Measurements.” Meas. Sci. Technol. 12:306-312.

Schuster GJ, SR Doctor and LJ Bond. 2004. “A System for High-Resolution, Nondestructive, Ultrasonic Imaging of Weld Grains.” IEEE Trans. Instr. Meas. 53(6):1526-1532.

Schwank JR, RD Nasby, SL Miller, MS Rodgers and PV Dressendorfer. 1990. “Total-Dose RadiationInduced Degradation of Thin Film Ferroelectric Capacitors.” IEEE. Trans. Nucl. Sci. 37(6):1703-1712.

Scott CC and S Ying. 1967. Development of the Under-Sodium Ultrasonic Scanner. APDA-210. Atomic Power Development Associates. AEC Contract No. AT(11-1)-865, PA No. 14.

Scott JF, CA Araujo, HB Meadows, LD McMillan and A Shawabkeh. 1989. "Radiation Effects on Ferroelectric Thin-Film Memories: Retention Failure Mechanisms.” J. Appl. Phys. 66(3):1444-1453.

Severson MR. 2004. An Experimental Design for Measuring In Situ Radiation Damage to Piezoelectric Transducer. Masters Thesis, Air Force Institute of Technology, Department of the Air Force Air University, Wright-Patterson Air Force Base, Ohio.

Smith RW. 1970. Effects of Gamma Radiation on the Piezoelectric Properties of Lithium Niobate. AEC Research and Development Report, BNWL-1436. Battelle Northwest, Richland, Washington.

Smith RW and CK Day. 1975a. High Temperature Ultrasonic Transducers for In-Sodium Service. HEDL-TME-75-21. Hanford Engineering Development Laboratory, Richland, Washington.

Smith RW and CK Day. 1975b. High Temperature Ultrasonic Transducers for In-sodium Service. HEDL-TME 75-21. Hanford Engineering Development Laboratory, Richland, Washington.

Smith RW, CK Day and WL Kelly. 1974. 1974 Ultrasonics Symposium Proceedings. IEEE Cat.\#74CHO 896-1SU. 
Swaminathan K, A Rajendran and G Elumalai. 1990. "The Development and Deployment of an Ultrasonic Under-Sodium Viewing System in the Fast Breeder Test Reactor.” IEEE. Trans. Nucl. Sci. 37(5):1571-1577.

Taguchi J, N Uesugi, T Miyazawa, K Sato and S Horikoshi. 1980. “An Ultrasonic Viewing System in Liquid Sodium.” IEEE. Trans. Nucl. Sci. 27(1):821-825.

Takeishi M, F Tsuri, Y Koketsu, T Kobayashi, H Ito, H Nishikawa, S Sasaki and J Uchi. 1997. "Development of Multiple Ultrasonic Transducer for Under Sodium Visual Observation.” Proceedings of ICONE 5 International Conference on Nuclear Engineering. May 26-30, 1997. Nice, France. ASME.

Turnbull DH and FS Foster. 1991. "Beam Steering with Pulsed Two-Dimensional Transducer Arrays.” IEEE Trans. Ultrason. Ferroelectrics Freq. Contr. 38(4):320-333.

Wang Z, Y Zhou and J Tian. 2008. "TOFD-Scan Imaging Based on Synthetic Aperture Focusing Technique.” Proceedings of the 17th World Conference on Nondestructive Testing. October 25-28, 2008. Shanghai, China.

Weast R, Ed. 1970. CRC Handbook of Chemistry \& Physics, 51st Edition. CRC Press, Boca Raton, Florida.

Wessels J. 1991. “Inservice Inspection of the Reactor Block of Sodium-Cooled Fast Breeder Reactors.” Nucl. Eng. Des. 130(1):33-42.

Zachariasz R, M Czerwiec and J Ilczuk. 2006. “Time Stability of Mechanical and Dielectric Parameters in the PZT Type Piezoceramics After Gamma Radiation: Revision.” Molecular and Quantum Acoustics 27:307-314. 


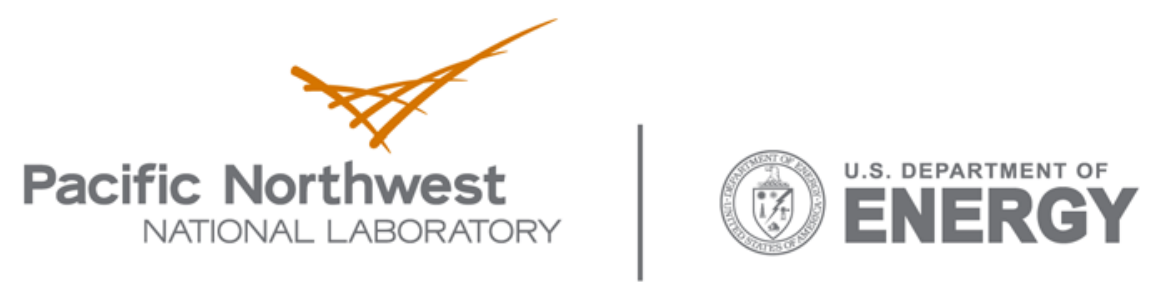

902 Battelle Boulevard

P.O. Box 999

Richland, WA 99352

1-888-375-PNNL (7665)

www.pnl.gov 